\title{
Modelling and Forecasting of Ikpoba River Discharge in the Niger Delta Region using Adaptive Neuro-Fuzzy Inference System (ANFIS)
}

\author{
Egbiki S. ${ }^{1, *}$, Ehiorobo J. O. ${ }^{2}$ and Izinyon O. C. ${ }^{3}$ \\ ${ }^{1}$ Department of Civil Engineering, Faculty of Engineering, Nigerian Maritime University, Okerenkoko, Delta \\ State, Nigeria \\ ${ }^{2,3}$ Department of Civil Engineering, Faculty of Engineering, University of Benin, Benin City, Edo State, Nigeria \\ Corresponding Author: *egbiki4u@yahoo.com
}

https://doi.org/10.36263/nijest.2020.02.0235

\begin{abstract}
In this study, the discharge of Ikpoba River was modelled and forecasted using adaptive neurofuzzy inference system (ANFIS). The river daily discharge, temperature and precipitation data sets from year 1991 to 1995 were used. In applying the ANFIS, five models stages; model-1, model-2, model-3, model-4 and model-5 were created using MATLAB. Model-1 to 4 were created using only the river discharge data, while model-5 was created by incorporating temperature and precipitation to cater for the effect of climate change into model-4. Five performance evaluation criteria, coefficient of correlation $(R)$, coefficient of determination $\left(R^{2}\right)$, mean square error (MSE), modelling efficiency $(E)$ and index of agreement (IOA) were used for comparative analysis. The results showed that though Model 1 to 4 were able to predict the river discharge accurately, model5 (when the effect of climate change was incorporated) performed better than the other four models with only discharge data. The training phase in model-5 showed an over-estimation of $0.043 \%$ of the observed target output sets while an over-estimation of $0.044 \%$ was observed in the testing phase. These are within acceptable error tolerance of $+/-10 \%$ for data validation. This information is useful for integrated water resources planning and management.
\end{abstract}

Keywords: Adaptive Neuro Fuzzy System, Forecasting, Performance Evaluation, Discharge

\subsection{Introduction}

Modelling and forecasting of river discharge is of vital importance in water resources management and hydrology. It helps in planning, operational analysis and efficient management of reservoirs, flood control measures, hydraulic design of structures such as dams, weirs, bridge crossings, sluice gates, barrages, stilling basins and spillways. It also plays vital roles in the management of hydropower and hydro peaking, modelling of river sediment transports, aggradations and armouring, modelling of river eco-hydraulic behaviour and aquatic lives and modelling of runoff and precipitation (Firat, 2007). Traditionally, many mathematical and conventional time series methods have been used in forecasting river discharges. Such methods include time series models using linear regression (LR) and multiple linear regressions (MLR) (Maier and Dandi, 1996), multivariate regression (MR) (Cogger, 2010) auto regression (AR) (Maity et al., 2010) and auto regressive moving average (ARMA) (Wong et al., 2010). Also, Auto regressive integrated moving average (ARIMA) (Maity et al., 2010), autoregressive moving average with exogenous inputs (ARMAX) (Wong et al., 2010), nearest neighbour method (NNM) (Emiroglu et al., 2011), support vector machine (SVM) and Monte Carlo simulation (Wang et al., 2009) have been extensively used. All these methods have one or other inherent problems in their effective forecasting because they assume linearity and stationarity in their modelling. These assumptions make the modelling of a non-linear and dynamic hydrological phenomenon produce inaccurate and ineffective forecasts (Firat, 2007).

In the search for effective methods for forecasting, soft computing methods have become handy. Recently, Artificial Intelligence (AI) models such as Artificial Neural Networks (ANN), Fuzzy Logic Inference System (FLIS) and Pattern Recognition (PR) which mimic the behaviour of the human 
brains have been increasingly and extensively used in the context of hydrological forecasting. The main advantages of these soft computing models are that they are data driven models and they don't need prior knowledge of the models under consideration (Chang and Chang, 2006).

Artificial Neural Networks (ANNs) which have been extensively used in water resources management, mimic the behaviour of the human brain. They are helpful and efficient in coping with systems that are deterministically or stochastically difficult to be described (Anctil and Rat, 2005). The Fuzzy logic Inference (FLI) approach is also one of the approaches that is gaining popularity in the field of water resources managements these days. It is inherently based on the linguistic uncertainty expression rather than numerical uncertainty.

Although both ANN and FLI have a lot of usefulness, yet there are still some problems associated with them (Owen et al., 2001). The main drawback of fuzzy logic modelling is that there is no systematic procedure when designing a fuzzy controller (Firat and Gungor, 2007). This is an advantage of ANN. The disadvantages in using ANNs include its "black box" nature, greater computational burden (an advantage of Fuzzy logic), proneness to over-fitting (an advantage of Fuzzy logic), and the empirical nature of model development. Since most of the advantages of ANN are the disadvantages of FLI and most of the advantages of FLI are the disadvantages of ANN; to overcome these problems and increase efficiency, both ANN and FL need to be coupled together. This hybrid combination is called Adaptive Neuro-Fuzzy Inference System (ANFIS) and is the application used in this study.

ANFIS is a well-known artificial intelligence technique that has been used recently in hydrological processes (Zounemat-Kermani and Teshnehalb, 2008). Use of this technique for rainfall-runoff and river flow time series predictions has been reported by many researchers (Valenca and Ludermir, 1999; Chang and Chen, 2001, 2006; Nayak et al., 2004a, 2004b, 2005). Tayfur and Singh (2006) used ANFIS models for simulating event-based rainfall-streamflow. Mukarji et al. (2009) applied ANFIS model to forecast stream flow for Ajay River Basin in Jharkhand, India. ANFIS has also been used in the following areas: optimal operation of multipurpose reservoir (Mehta and Jain, 2009), hydrological time series prediction (Zounemat-Kermani and Teashnehalb, 2008), municipal water consumption modeling (Yurdusev and Firat, 2009), stream flow forecasting (Swain and Umamahesh, 2004), sediment volume prediction (Cigizoglu and Alp, 2006), ground water flow prediction, reconstruction of missing precipitation events (Dastorani et al., 2010), short term water level prediction (Erinawati and Fenton, 2012), prediction of scour depth at culvert outlets (Azamathulla and Ghani, 2011) and Evapotranspiration prediction (Firat, 2007).

\subsection{Methodology}

\subsection{Study area}

Ikpoba River is situated within the rainforest belt of Edo State and the Western Littoral hydrological area (HA-6) of Nigeria (Akintola, 1986). The Western Littoral hydrological area (HA-6) is one of the eight hydrological areas (HAs) into which Nigeria is subdivided. The gauging station from which the data for this study were collected is located along Ikpoba River in Benin City which is about $316 \mathrm{~km}$ due East of Lagos. The River rises from the Ishan Plateau in the Northern part and flows in south west direction in a steeply incised valley and through sandy areas before passing through Benin City and joining the Ossiomo River Basin. The river is situated between Latitude $6^{\circ} 19^{\prime} 41.71 \mathrm{~N}^{\prime \prime}$ to $6^{\circ} 54^{\prime} 53.41 \mathrm{~N}^{\prime \prime}$ and Longitude: $5^{\circ} 38^{\prime} 45.39 \mathrm{E} "$ to $5^{\circ} 55^{\prime} 49.77 \mathrm{E} "$ and its drainage area is $922 \mathrm{~km}^{2}$ (BORBDA, 2005). Figure 1 shows the location map of the study area and Table 1 shows the parameters of the hydrological gauging station. 


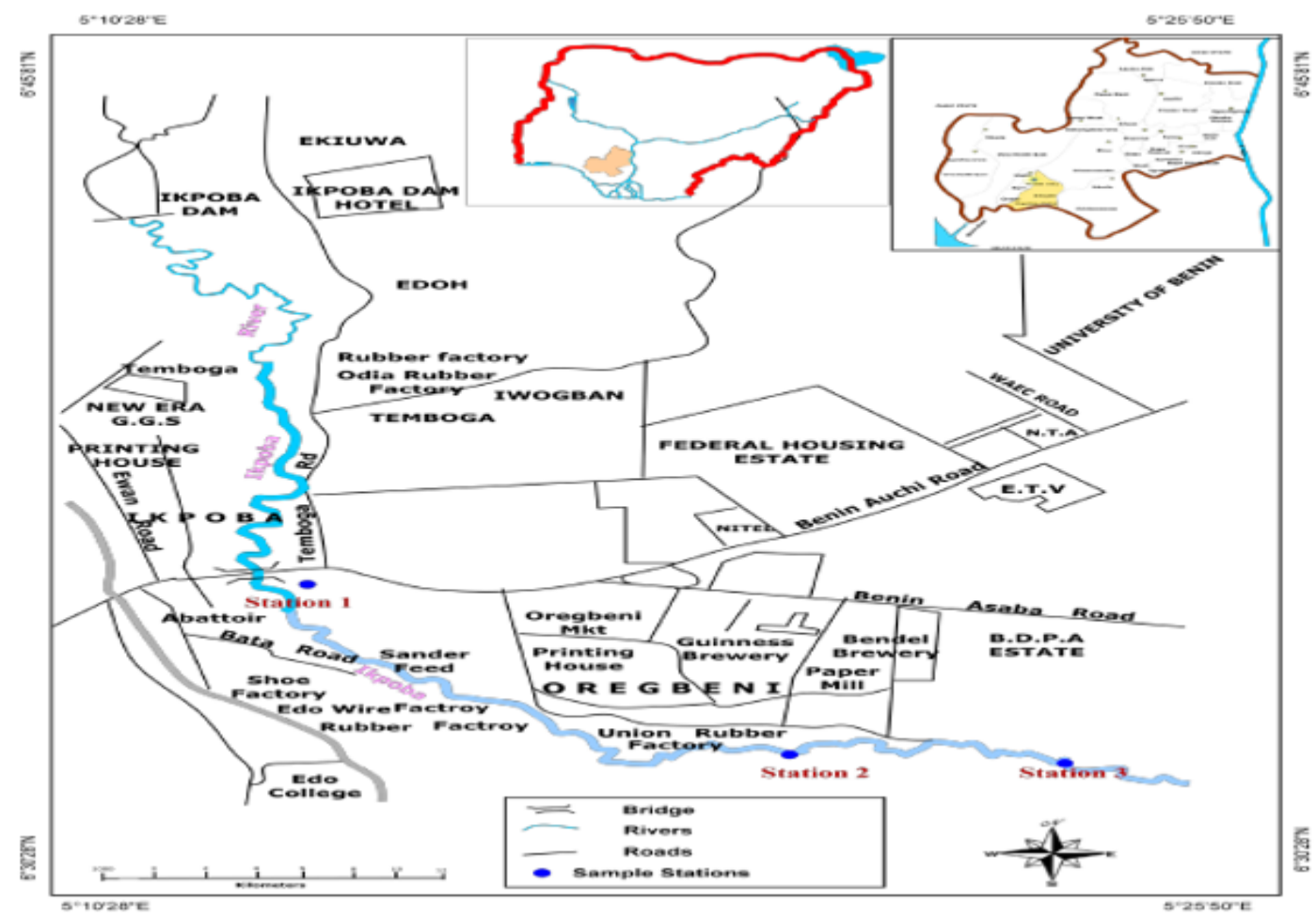

Figure 1: Location map of part of Ikpoba River in Benin City

Table 1: Ikpoba River hydrological gauging station parameters

\begin{tabular}{|l|l|l|l|l|l|}
\hline Location of Station & Location & Basin & Latitude & Longitude & Drainage Area $\left(\mathrm{km}^{2}\right)$ \\
\hline Ikpoba River at Benin City & Edo, Nigeria & Ossiomo & $6^{0} 20^{\prime} \mathrm{N}$ & $5^{0} 39^{\prime} \mathrm{E}$ & 922 \\
\hline
\end{tabular}

\subsection{Materials}

The discharge data sets used for this study were obtained from Benin-Owena River Basin in BeninCity, Edo State while the precipitation and temperature date sets were obtained from NIMET, Lagos office. The only available data sets used were the daily discharges, temperatures and precipitations of Ikpoba river from 1991 to 1995 (5 years).

\subsection{Methods}

The general structure of the forecasting models is given in Equations 1-3 below and the structures of the forecasting models are given in Table 2.

$Q(t)=Q(t-1)+Q(t-2)+\cdots Q(t-n)$

$T(t)=T(t-1), T(t-2)+\cdots T(t-n)$

$P(t)=P(t-1), P(t-2)+\cdots P(t-n)$

Where $\mathrm{n}$ is the number of year(s) under forecast.

Table 2: Structure of the forecasting models

\begin{tabular}{|l|l|l|l|l|l|}
\hline $\mathrm{S} / \mathrm{N}$ & Model & $\begin{array}{l}\text { Input } \\
\text { Parameters }\end{array}$ & Input Structure & $\begin{array}{l}\text { No of Input } \\
\text { Variables }\end{array}$ & $\begin{array}{l}\text { Target } \\
\text { Output }\end{array}$ \\
\hline 1 & Model-1 & $\mathrm{Q}$ & $\mathrm{Q}(\mathrm{t}-1)$ & 1 & $\mathrm{Q}(\mathrm{t})$ \\
\hline 2 & Model-2 & $\mathrm{Q}$ & $\mathrm{Q}(\mathrm{t}-1), \mathrm{Q}(\mathrm{t}-2)$ & 2 & $\mathrm{Q}(\mathrm{t})$ \\
\hline 3 & Model-3 & $\mathrm{Q}$ & $\mathrm{Q}(\mathrm{t}-1), \mathrm{Q}(\mathrm{t}-2), \mathrm{Q}(\mathrm{t}-3)$ & 3 & $\mathrm{Q}(\mathrm{t})$ \\
\hline 4 & Model-4 & $\mathrm{Q}$ & $\mathrm{Q}(\mathrm{t}-1), \mathrm{Q}(\mathrm{t}-2), \mathrm{Q}(\mathrm{t}-3), \mathrm{Q}(\mathrm{t}-4)$ & 4 & $\mathrm{Q}(\mathrm{t})$ \\
\hline 5 & Model-5 & $\mathrm{T}$ & $\mathrm{T}(\mathrm{t}-1), \mathrm{T}(\mathrm{t}-2), \mathrm{T}(\mathrm{t}-3), \mathrm{T}(\mathrm{t}-4)$ & 12 & $\mathrm{Q}(\mathrm{t})$ \\
& & $\mathrm{P}$ & $\mathrm{P}(\mathrm{t}-1), \mathrm{P}(\mathrm{t}-2), \mathrm{P}(\mathrm{t}-3), \mathrm{P}(\mathrm{t}-4)$ & & \\
\hline
\end{tabular}

Where, $\mathrm{Q}(\mathrm{t})$ represents the river discharge at time $(\mathrm{t}), 1995 ; \mathrm{T}(\mathrm{t}-1), \mathrm{T}(\mathrm{t}-2), \mathrm{T}(\mathrm{t}-3), \mathrm{T}(\mathrm{t}-4) ; \mathrm{P}(\mathrm{t}-1), \mathrm{P}(\mathrm{t}-$ 2), $\mathrm{P}(\mathrm{t}-3), \mathrm{P}(\mathrm{t}-4)$ and $\mathrm{Q}(\mathrm{t}-1), \mathrm{Q}(\mathrm{t}-2), \mathrm{Q}(\mathrm{t}-3), \mathrm{Q}(\mathrm{t}-4)$ represent the temperature, the precipitation and the 
river discharge at one time step (1994), second time steps (1994 and 1993), third time steps (1994, 1993 and 1992) and fourth time steps (1994, 1993, 1992 and 1991) lag respectively.

\subsection{Model application}

The following standard procedures for designing networks models to solve problems for time series analysis and forecast using ANFIS in MATLAB were utilized (Anctil and Rat, 2005).

Firstly, the selected input data sets and the target output data sets for each of the five models Model-1 to 5 were fed into ANFIS graphical user interface (GUI) of MATLAB.

Secondly, the fuzzy logic inference for fuzzification processes (crisps-fuzzy sets) was specified. The first order Sugeno fuzzy logic inference (linear function) was used for the five models. The number of fuzzy membership functions for each input model was considered to be three (3) and the generalized bell (gbell) type of membership function which is a direct generalization of the Cauchy distribution as used in the probability theory with three parameters was used for all the five models. Due to its smoothness and concise expression, it is popularly used in many hydrological applications to specify the fuzzy sets (Jang and Sun, 1995). The outputs function of the ANFIS models were considered as a linear type for all the five models.

Thirdly, the learning algorithm to initialize the input data structures to generate the fuzzy sets used the grid partitioning method which helped to partition the data into various groups such as training, testing and validation (checking). Various percentages for the training data set, testing data set and validation data set were randomly selected. The partition of $70 \%$ training data set, $15 \%$ testing data set and $15 \%$ validation data set were found to give optimal results. The $70 \%$ training data set were presented to the ANFIS network during training and the networks were adjusted according to their errors. The $15 \%$ validation data set were used to measure the network generalizations and to halt the training when generations stopped improving. The remaining $15 \%$ testing data set have no effects on the training and so provide an independent measure of the network performance during and after training. The parameters of the membership functions were adjusted and trained using hybrid algorithm which is a combination of least square- Levenberg-Marquardt algorithm and gradient descent backpropagation algorithm. Finally, the models were deffuzified. The number of epochs used was 10 , the error tolerance limit used was zero, the AND implication method used was PROD (product) and the deffuzification method used was the weighted average (wtaver) for all the five models. The performances of the ANFIS network models were compared by using five statistical goodness of fit measures such as coefficient of correlation $(R)$, coefficient of determination $\left(R^{2}\right)$, mean square error (MSE), Nash-Sutcliffe efficiency (E) and index of agreement (IOA).

Figures 2 to 11 show the network models for all the five models using ANFIS.

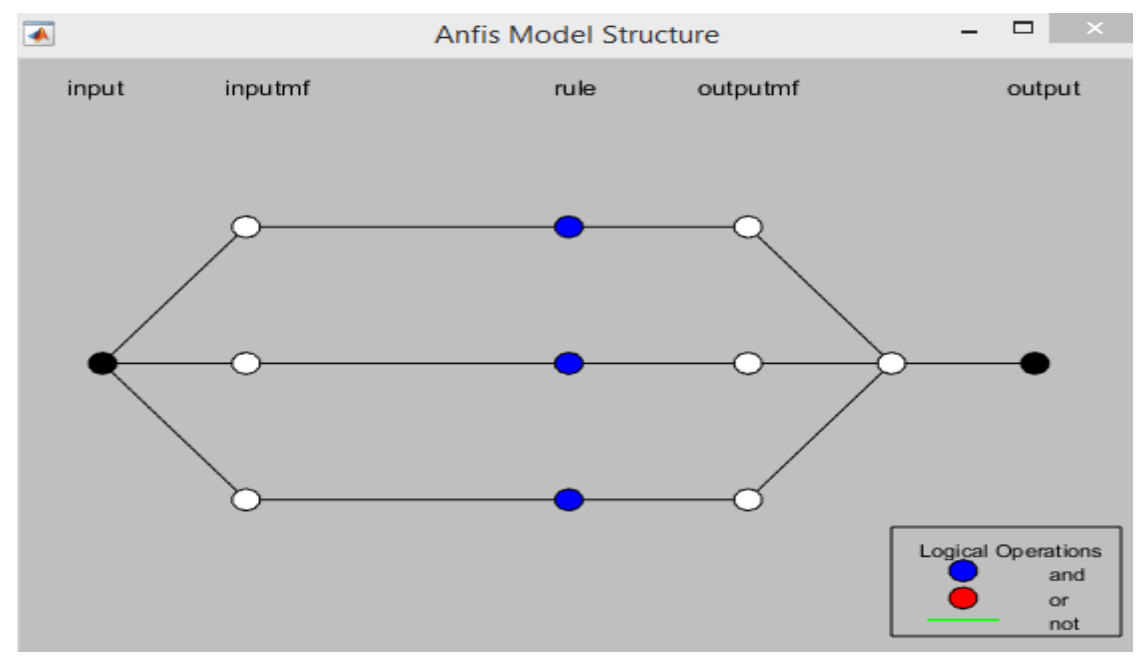

Figure 2: ANFIS model network for Model-1 (1 input data) 


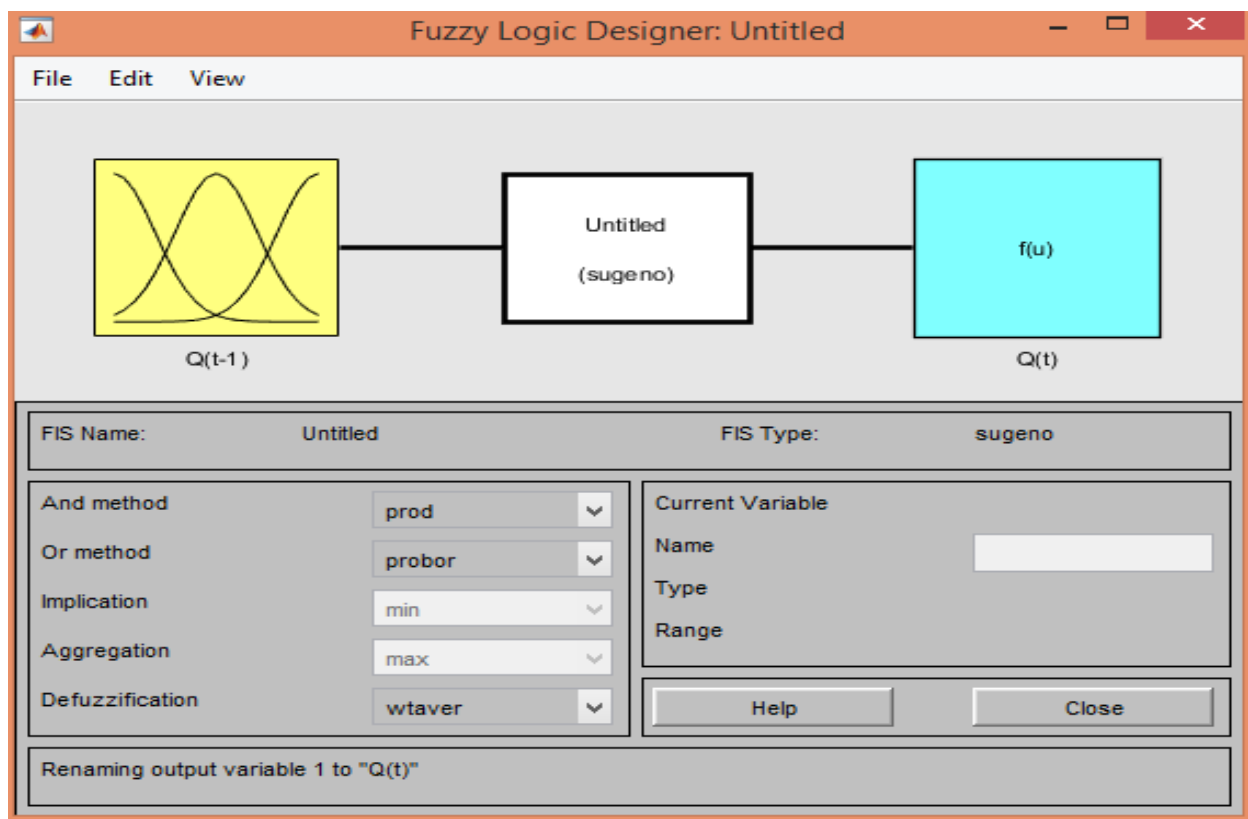

Figure 3: ANFIS deffuzification process for Model-1

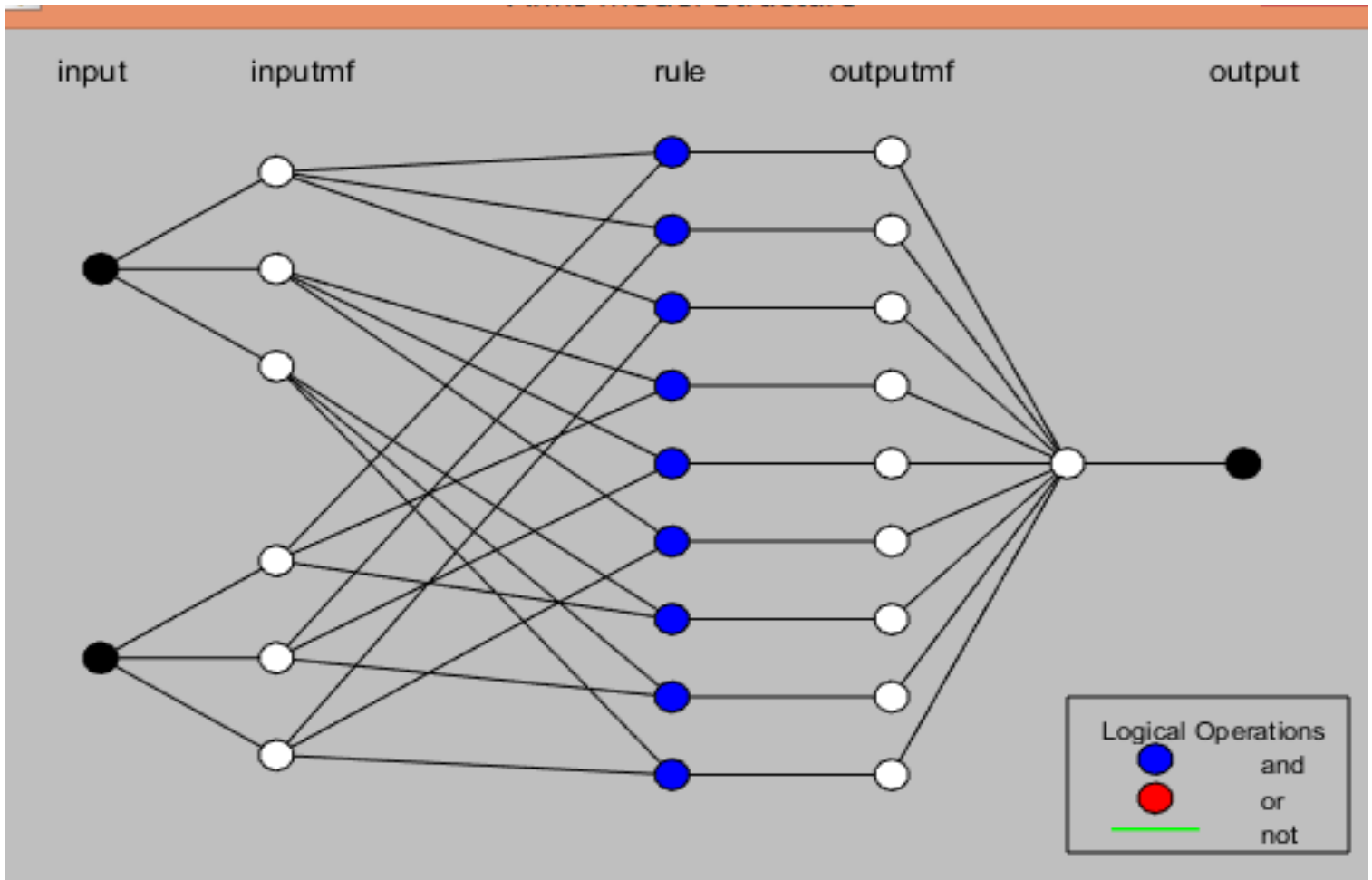

Figure 4: ANFIS model network for Model-2 (2 inputs data) 


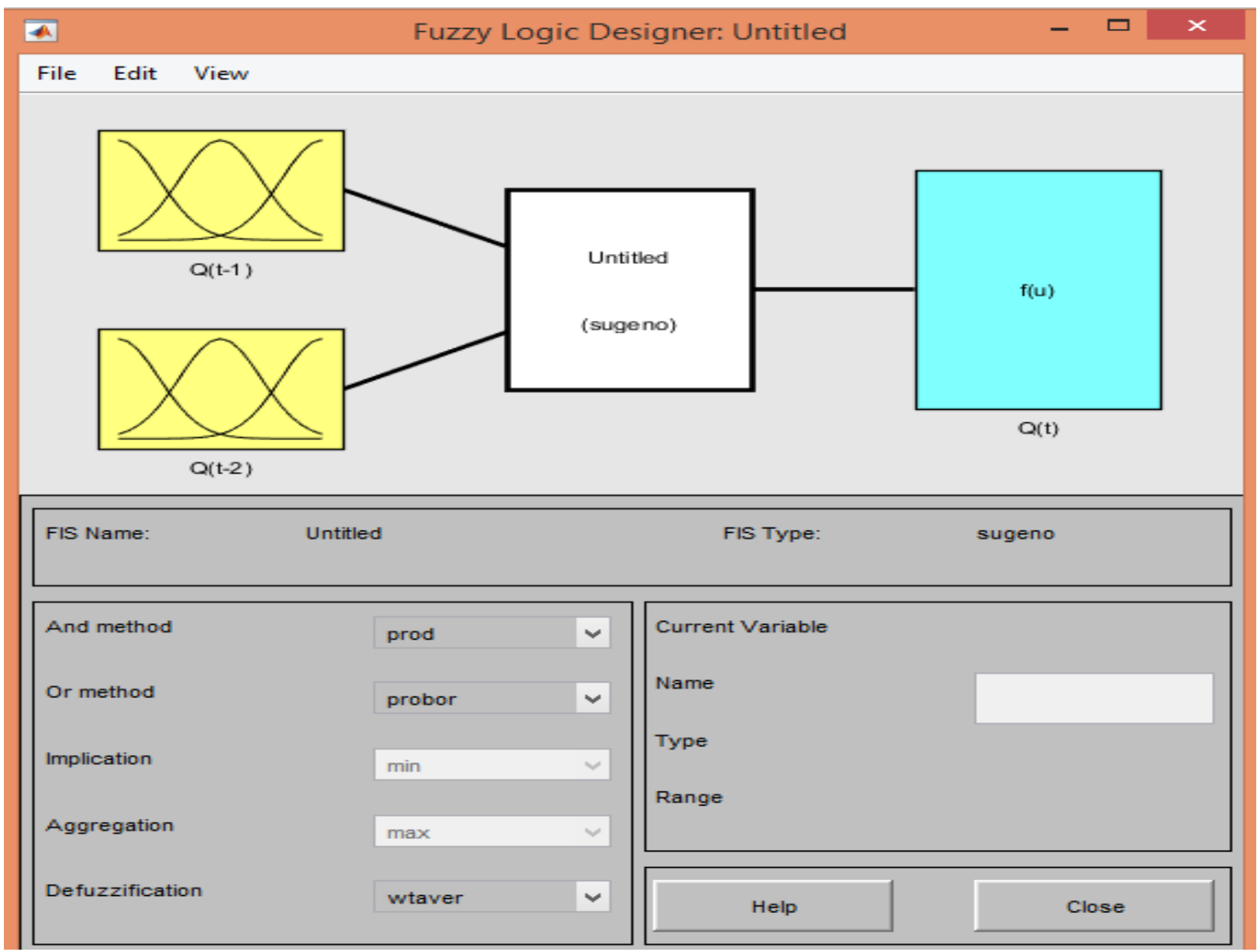

Figure 5: ANFIS deffuzification process for Model-2

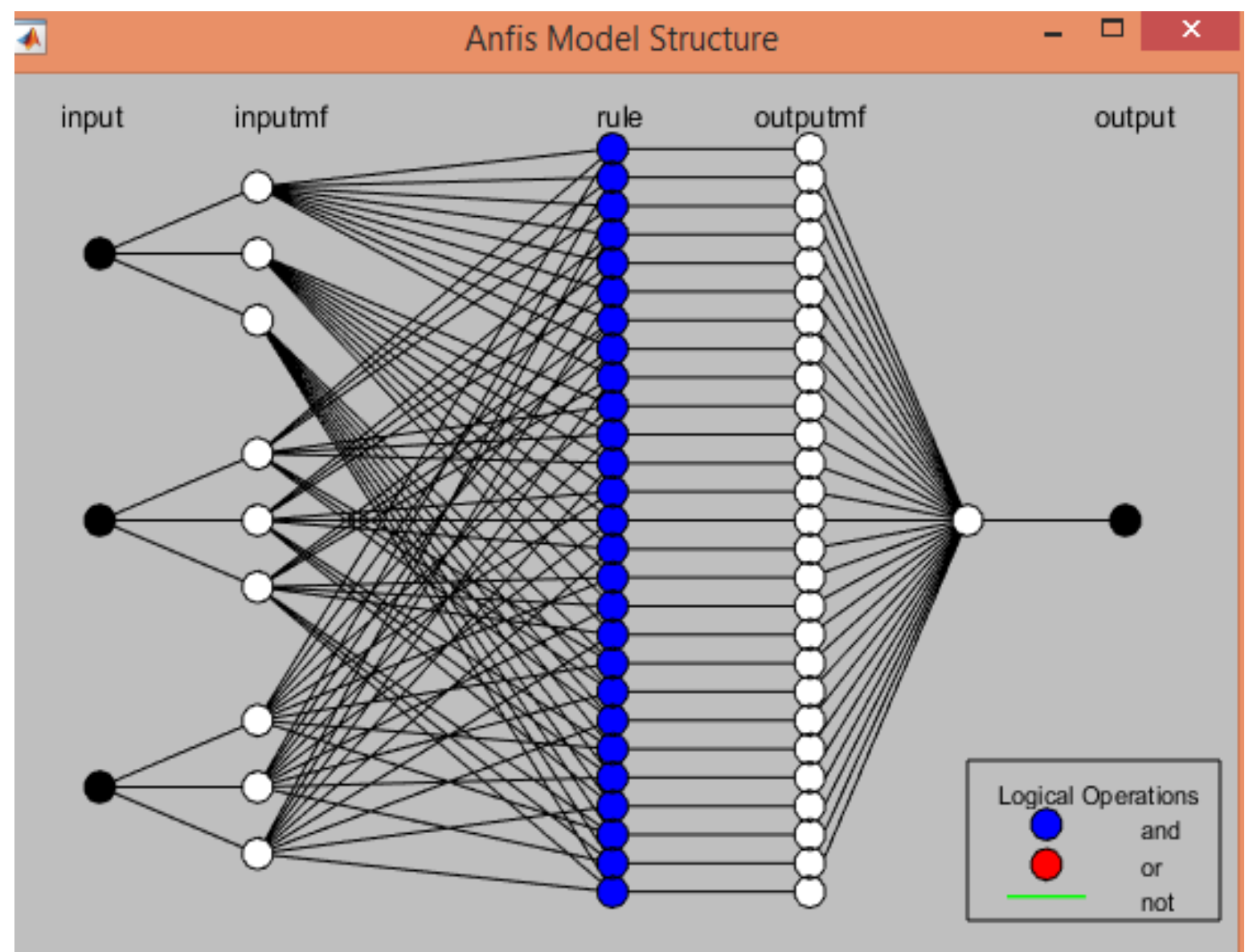

Figure 6: ANFIS model network for Model-3 (3 inputs data) 


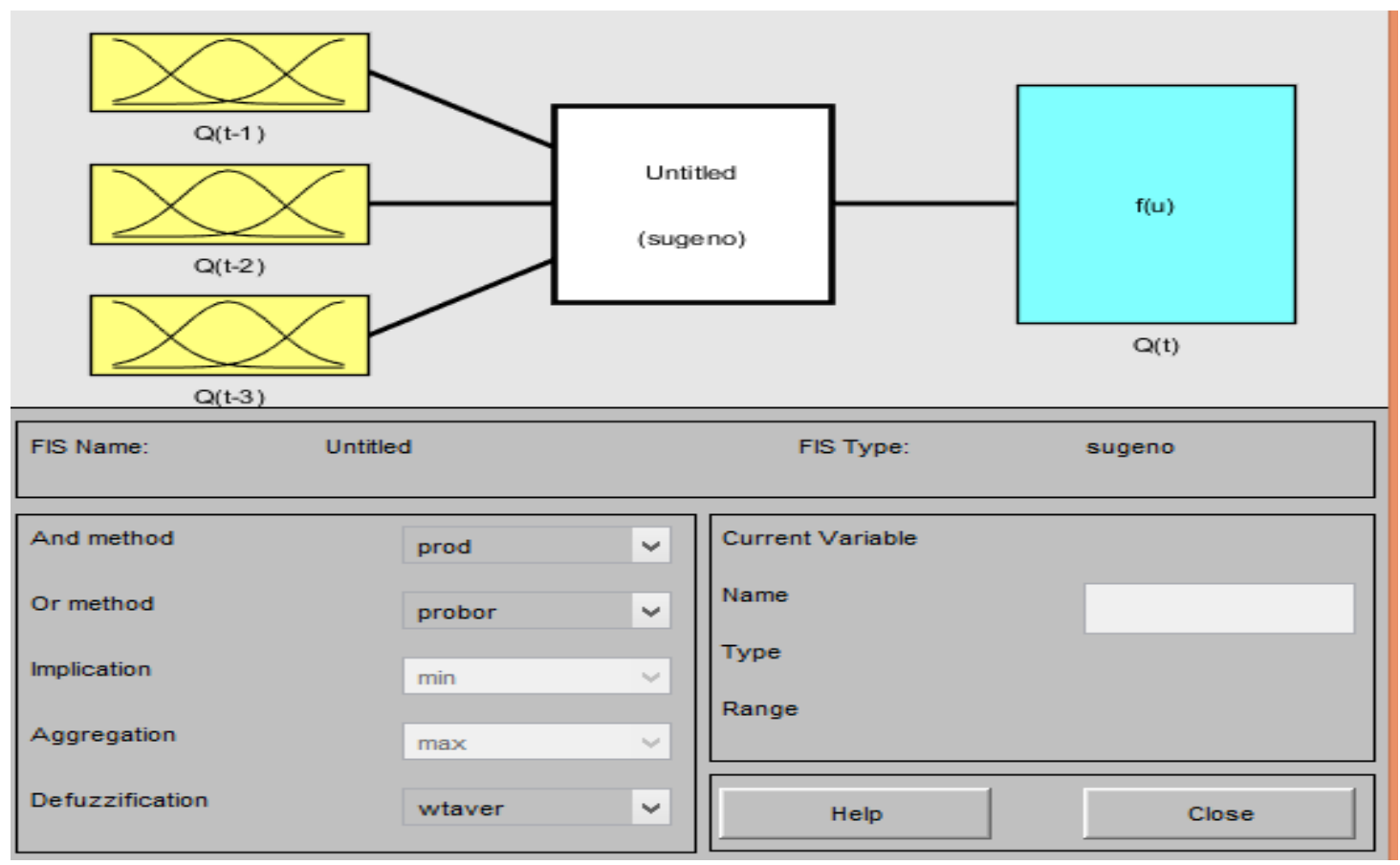

Figure 7: ANFIS deffuzification process for Model-3

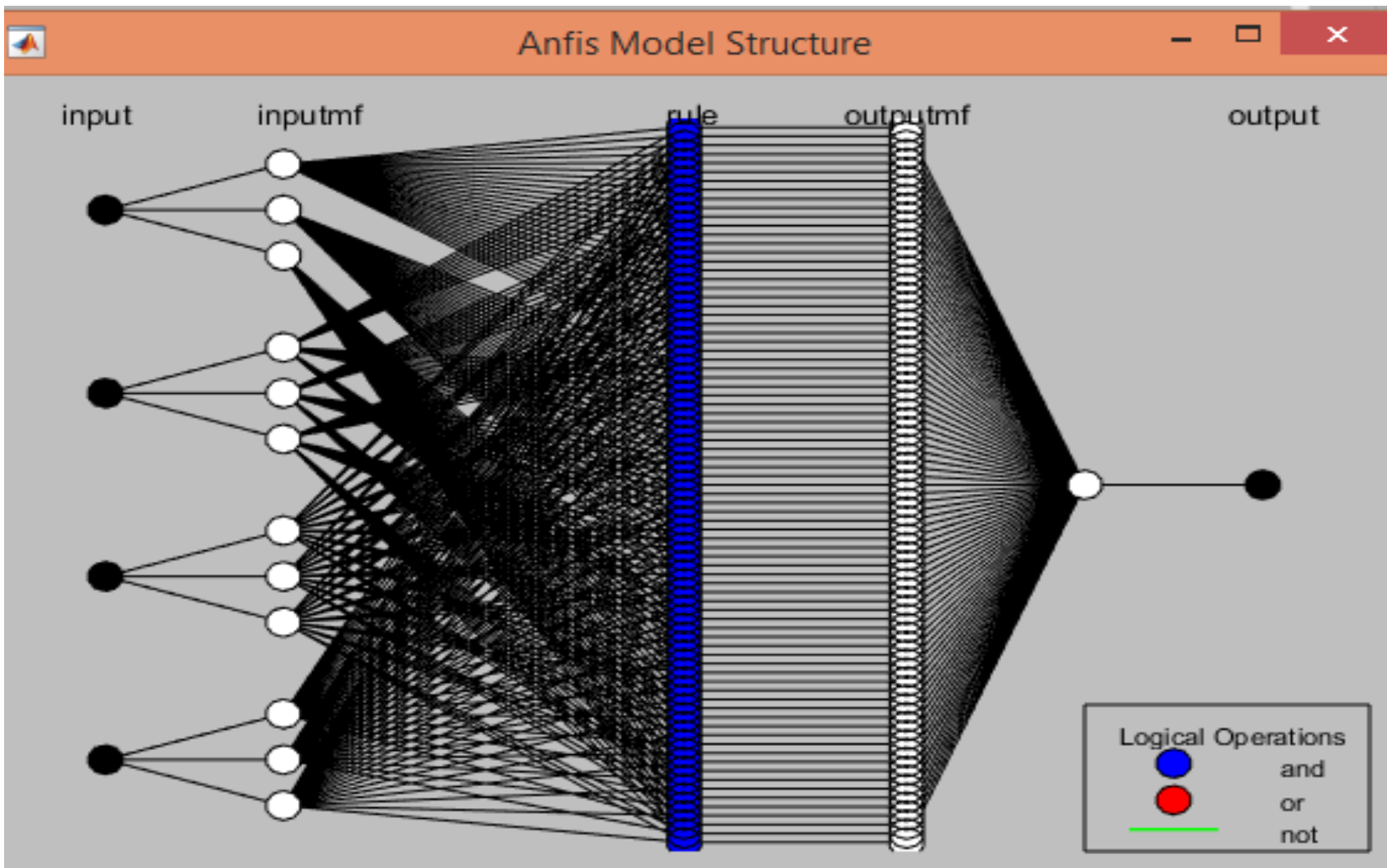

Figure 8: ANFIS model network for Model-4 (4 inputs data) 


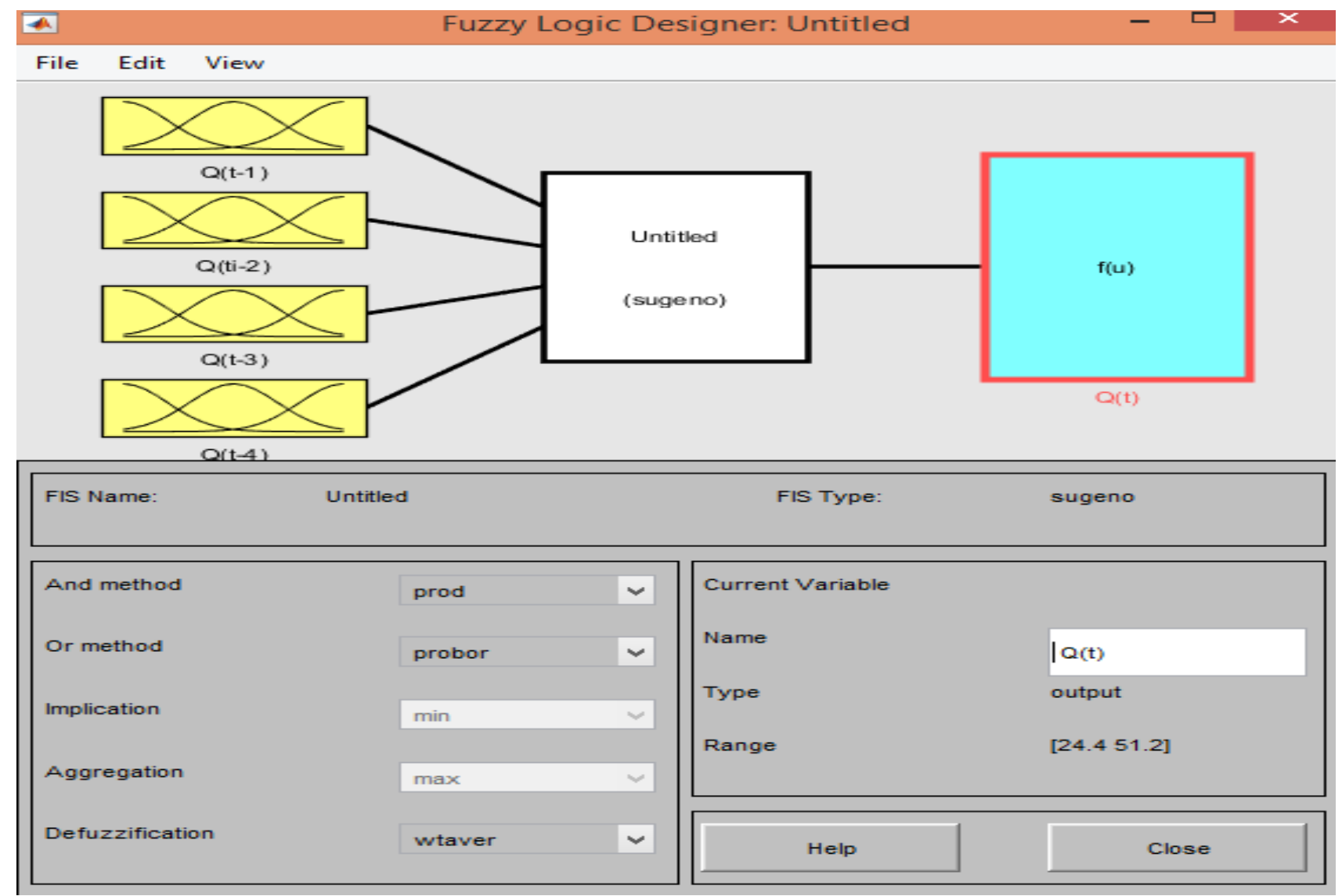

Figure 9: ANFIS defuzzification process for Model-4

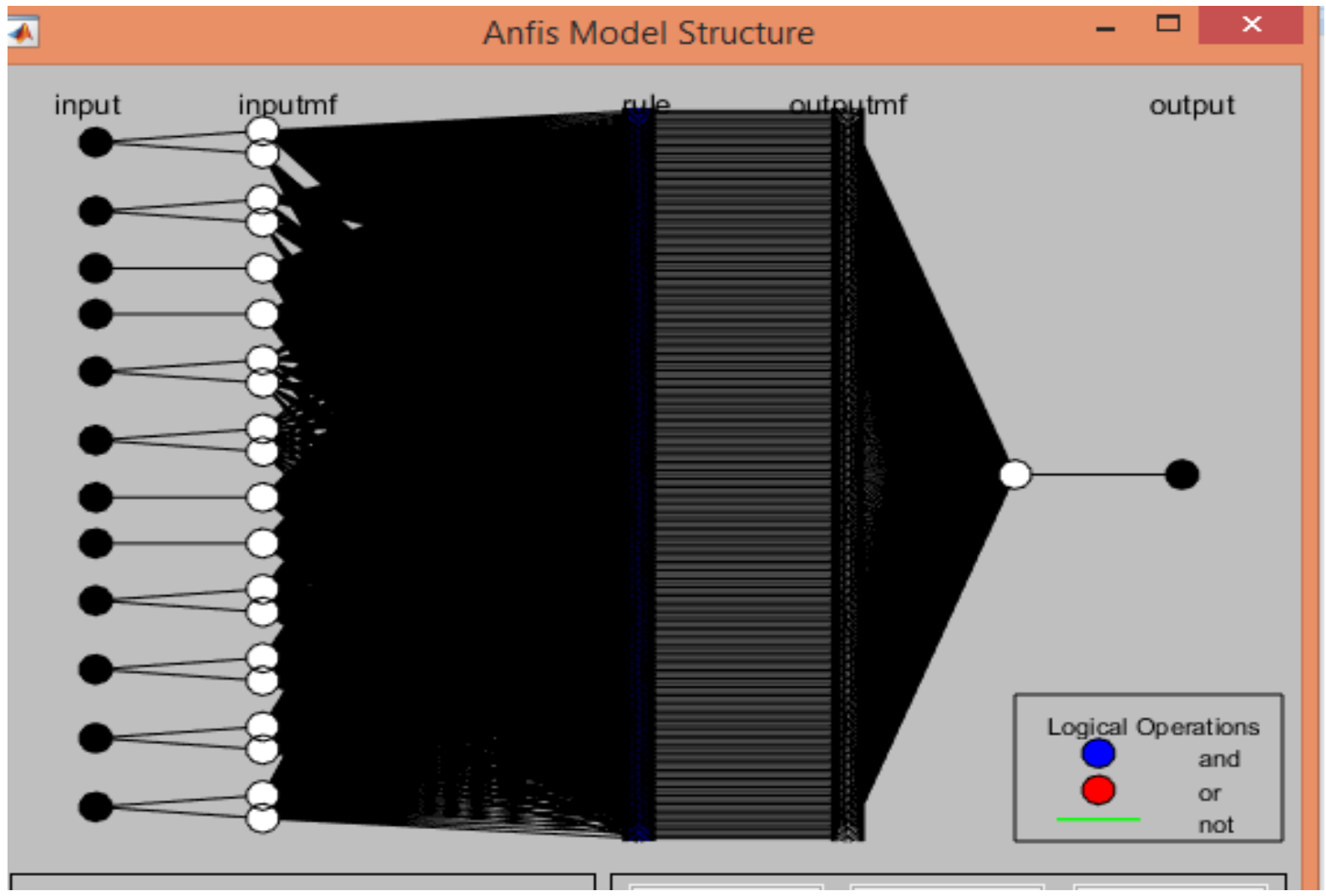

Figure 10: ANFIS model network for Model-5 (12 inputs data) 


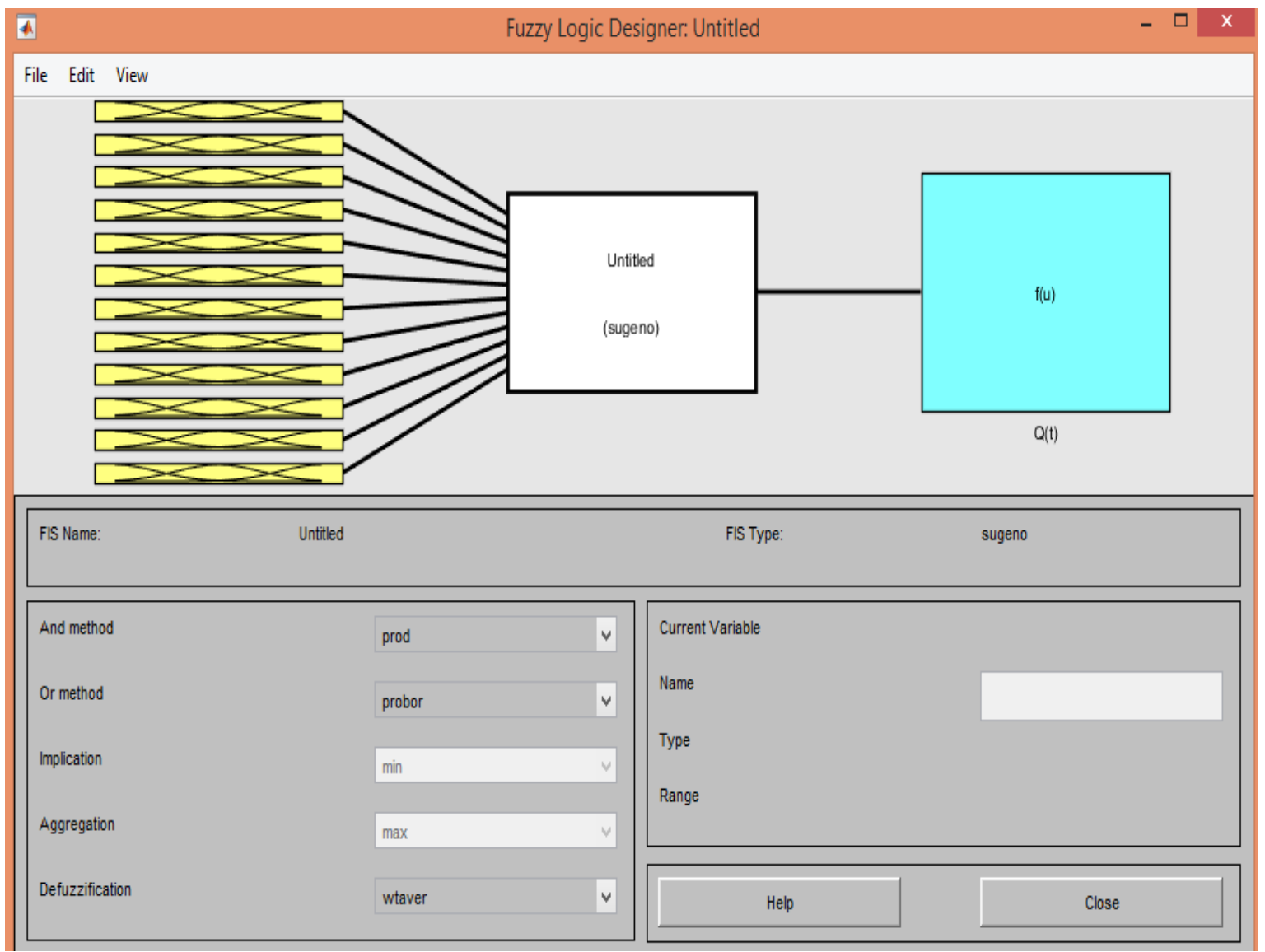

Figure 11: ANFIS deffuzification process for Model-5

\subsection{Results and Discussions}

The results obtained for Model-1 to Model 5 using ANFIS are presented and discussed below. The coefficient of correction (R) and the mean square error (MSE) were used to monitor the performance during training phase, testing phase and combined phase (training, testing and validation) using MATLAB training interface. Validation data sets were used to check and control the potential of the network models to over fit the data during training; hence they were not discussed separately like the training and testing data sets. Coefficient of determination $\left(\mathrm{R}^{2}\right)$, modelling efficiency $(E)$ and index of agreement (IOA) were further used to make detail comparative analysis.

\section{Model-1:}

The results from Model 1 are shown in Figure 12 and 13.

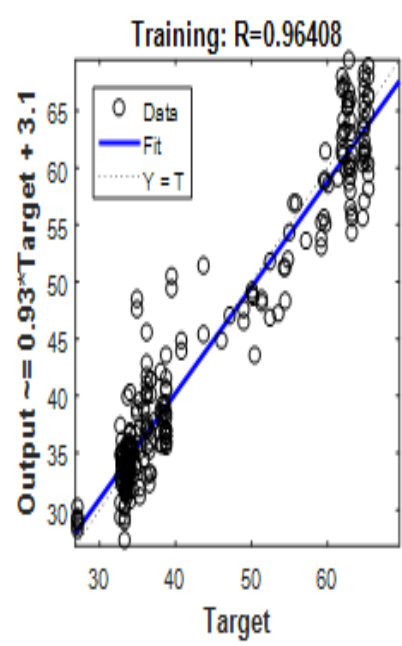

(a) Training

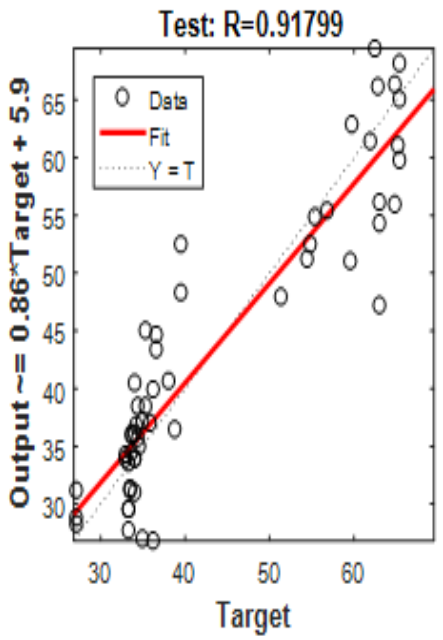

(b) Testing

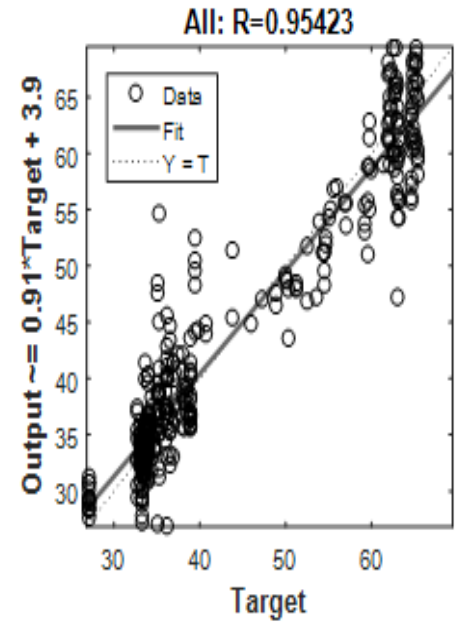

(c) All

Figure 12: Performance in model-1 using $R$ as an evaluation criteria 


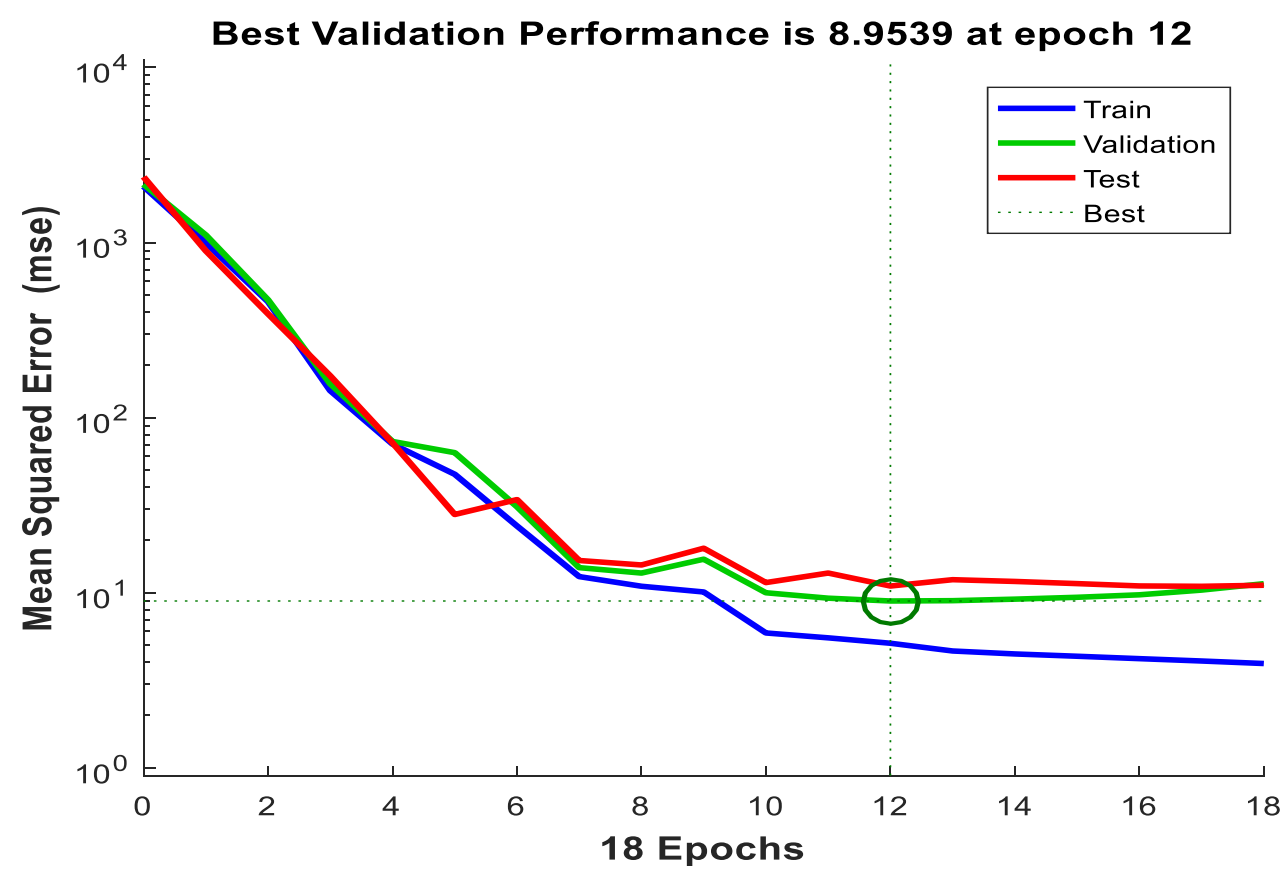

Figure 13: Performance in model-1 using MSE as an evaluation criteria

From Figure 12, the values of $\mathrm{R}$ in the training, testing and combined phases are 0.964, 0.918 and 0.954 respectively. The higher the value of $\mathrm{R}$ the better the result. This showed that the result was better in the training phase, follow by combined phase and least in the testing phase. These values were further confirmed with the values of MSE (Figure 13) $6.50 \mathrm{~m}^{3} / \mathrm{s}, 10.55 \mathrm{~m}^{3} / \mathrm{s}$ and $8.950 \mathrm{~m}^{3} / \mathrm{s}$ in the training, testing and combined phase respectively. The lower the value of MSE the better the result. Three other performance criteria (coefficient of determination, $\mathrm{R}^{2}$; modelling efficiency, $\mathrm{E}$ and index of agreement, IOA) were further used to confirm the validity of these results. In the training phase, the results are $\left(\mathrm{R}^{2}=0.929, \mathrm{E}=0.932\right.$ and IOA $\left.=0.731\right)$, testing phase $\left(\mathrm{R}^{2}=0.843, \mathrm{E}=0.911\right.$ and IOA $=0.710)$ and combined phase $\left(\mathrm{R}^{2}=0.910, \mathrm{E}=0.921\right.$ and IOA $\left.=0.730\right)$. These again confirmed the previous results as the higher the value of $\mathrm{R}^{2}, \mathrm{E}$ and IOA, the better the result. Based on the criteria used, the results showed that Model 1 was able to predict the river discharge with more than $70 \%$ degree of accuracy.

\section{Model-2:}

The results from Model 2 are shown in Figure 14 and 15.

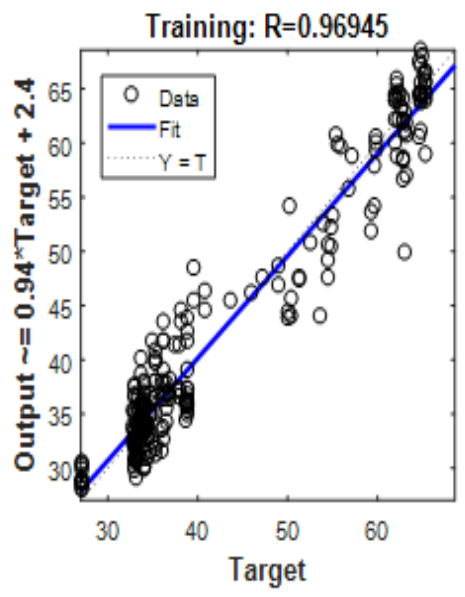

(a) Training

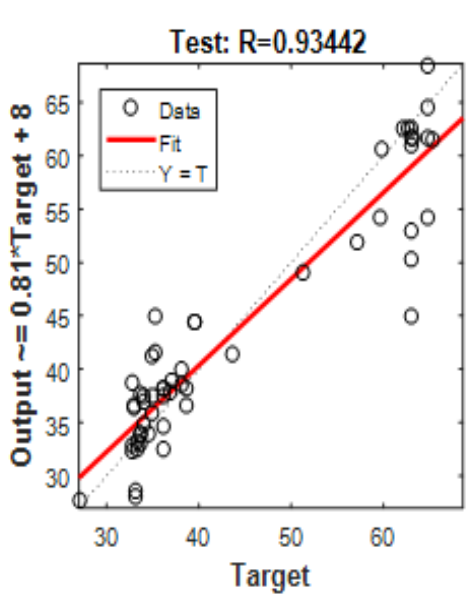

(b) Testing

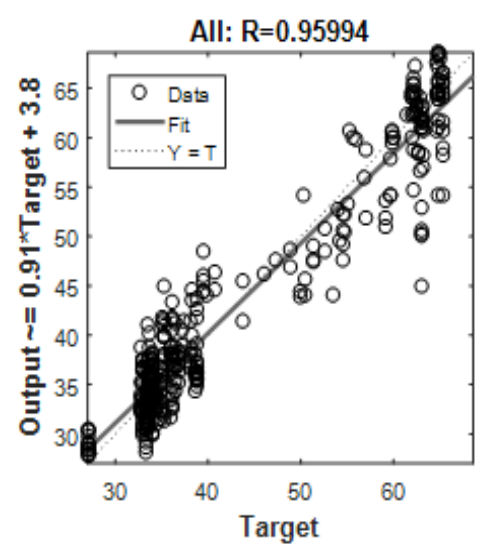

(c) All

Figure 14: Performance in model-2 using $\mathrm{R}$ as an evaluation criteria 


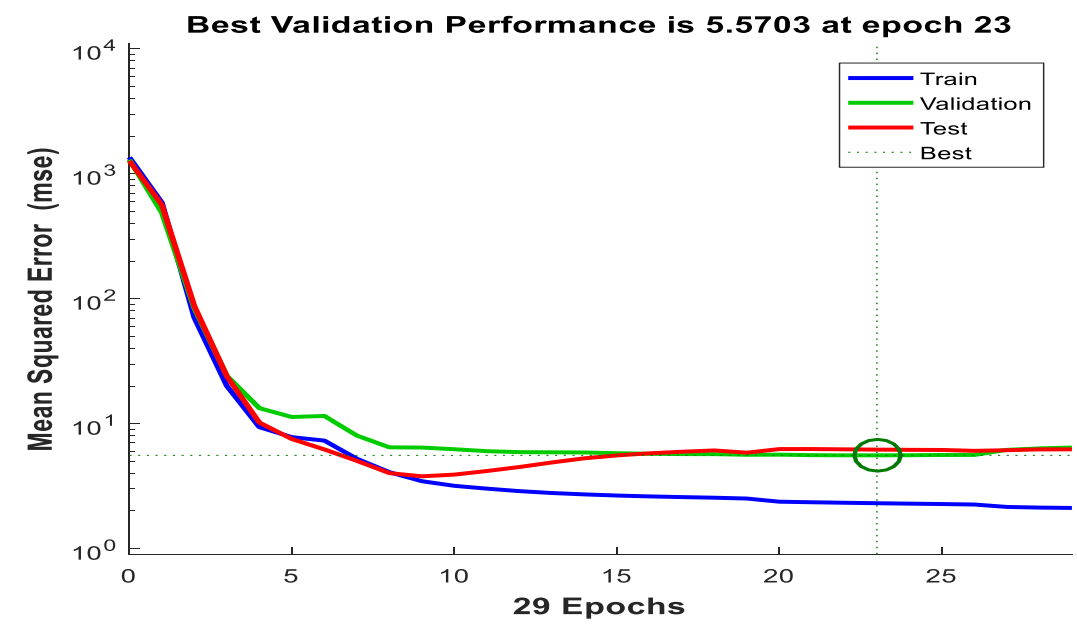

Figure 15: Performance in model-2 using MSE as an evaluation criteria

From Figure 14, the values of $\mathrm{R}$ in the training, testing and combined phases are 0.969, 0.934 and 0.960 respectively. The higher the value of $\mathrm{R}$ the better the result. This showed that the result was better in the training phase, follow by combined phase and least in the testing phase. These values were further confirmed with the values of MSE (Figure 15) $3.77 \mathrm{~m}^{3} / \mathrm{s}, 6.68 \mathrm{~m}^{3} / \mathrm{s}$ and $5.57 \mathrm{~m}^{3} / \mathrm{s}$ in the training, testing and combined phase respectively. The lower the value of MSE the better the result. Three other performance criteria (coefficient of determination, $\mathrm{R}^{2}$; modelling efficiency, $\mathrm{E}$ and index of agreement, IOA) were further used to confirm the validity of these results. In the training phase, the results are $\left(\mathrm{R}^{2}=0.939, \mathrm{E}=0.952\right.$ and $\left.\mathrm{IOA}=0.735\right)$, testing phase $\left(\mathrm{R}^{2}=0.872, \mathrm{E}=0.942\right.$ and $\mathrm{IOA}=$ $0.726)$ and combined phase $\left(R^{2}=0.922, E=0.948\right.$ and IOA $\left.=0.732\right)$. These confirmed the previous results as the higher the value of $\mathrm{R}^{2}, \mathrm{E}$ and IOA, the better the result. But the results from Model 2 improved better than that of Model 1 when the five performance criteria were compared as indicated by high values of ( $R, R^{2}, E$ and IOA) and lower values of (MSE). This indicated that the more the dataset, the better the results.

\section{Model-3:}

The results from Model 3 are shown in Figure 16 and 17.

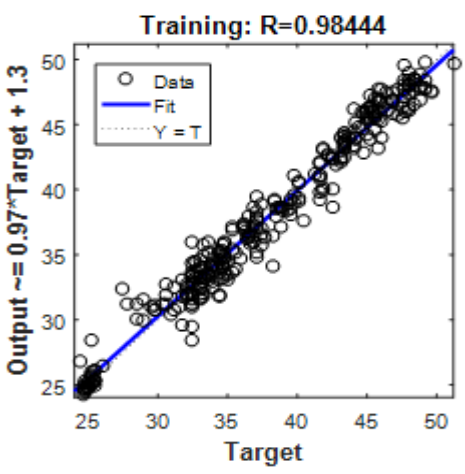

(a) Training

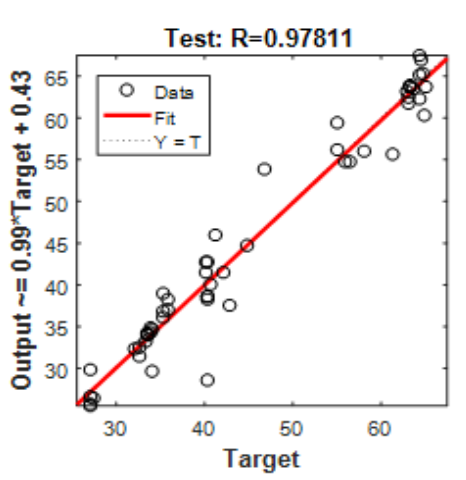

(b) Testing

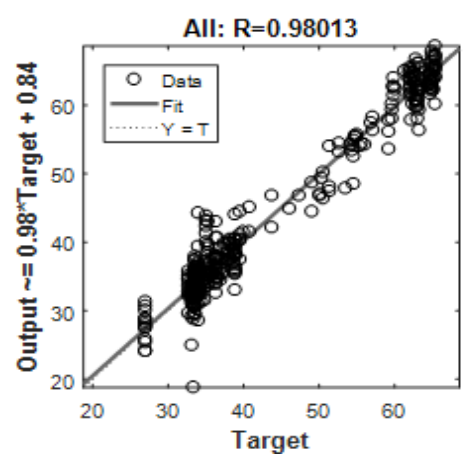

(c) All

Figure 16: Performance in model-3 using $R$ as an evaluation criteria 


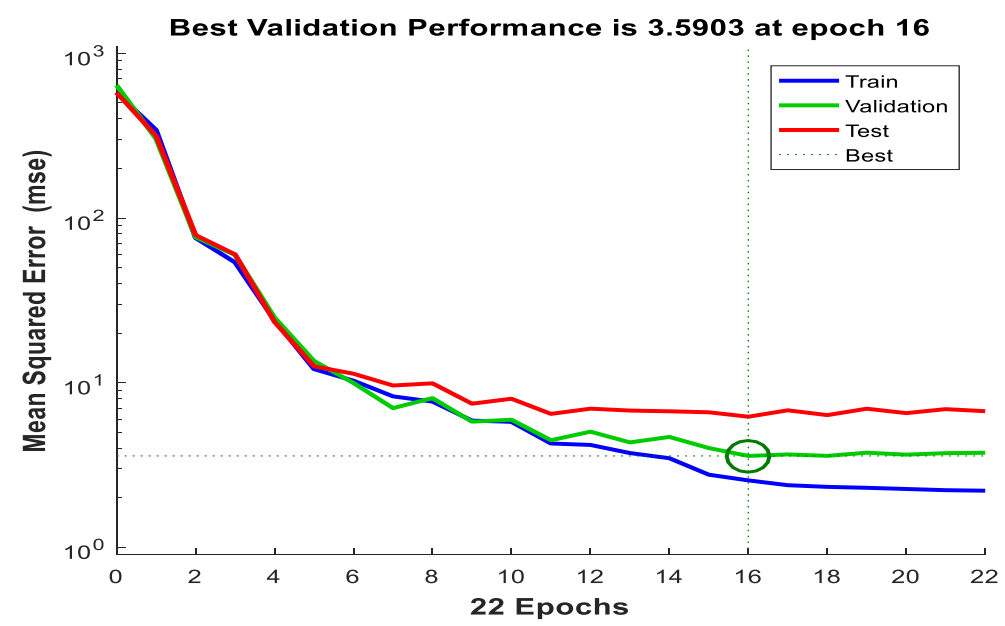

Figure 17: Performance in model-3 using MSE as an evaluation criteria

From Figure 16, the values of $\mathrm{R}$ in the training, testing and combined phases are 0.984, 0.978 and 0.980 respectively. The higher the value of $\mathrm{R}$ the better the result. This showed that the result was better in the training phase, follow by combined phase and least in the testing phase. These values were further confirmed with the values of MSE (Figure 17) $3.15 \mathrm{~m}^{3} / \mathrm{s}, 5.85 \mathrm{~m}^{3} / \mathrm{s}$ and $3.59 \mathrm{~m}^{3} / \mathrm{s}$ in the training, testing and combined phase respectively. The lower the value of MSE the better the result. Three other performance criteria (coefficient of determination, $\mathrm{R}^{2}$; modelling efficiency, $\mathrm{E}$ and index of agreement, IOA) were further used to confirm the validity of these results. In the training phase, the results are $\left(\mathrm{R}^{2}=0.968, \mathrm{E}=0.962\right.$ and $\left.\mathrm{IOA}=0.744\right)$, testing phase $\left(\mathrm{R}^{2}=0.956, \mathrm{E}=0.953\right.$ and $\mathrm{IOA}=$ $0.738)$ and combined phase $\left(\mathrm{R}^{2}=0.960, \mathrm{E}=0.961\right.$ and IOA $\left.=0.743\right)$. These confirmed the previous results as the higher the value of $\mathrm{R}^{2}, \mathrm{E}$ and IOA, the better the result. But the results from Model 3 improved better than that of Model 1 and Model 2 when the five performance criteria were compared as indicated by high values of (R, $\mathrm{R}^{2}, \mathrm{E}$ and IOA) and lower values of (MSE). This indicated that the more the dataset, the better the results.

\section{Model-4:}

The results from Model 4 are shown in Figure 18 and 19.

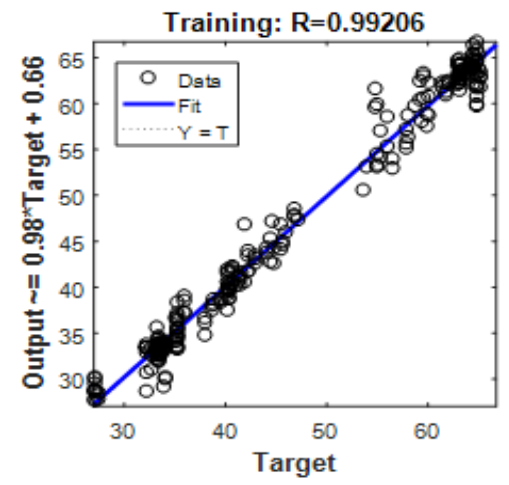

(a) Training

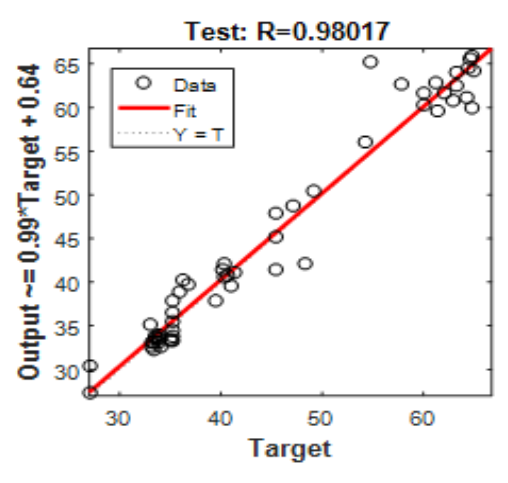

(b) Testing

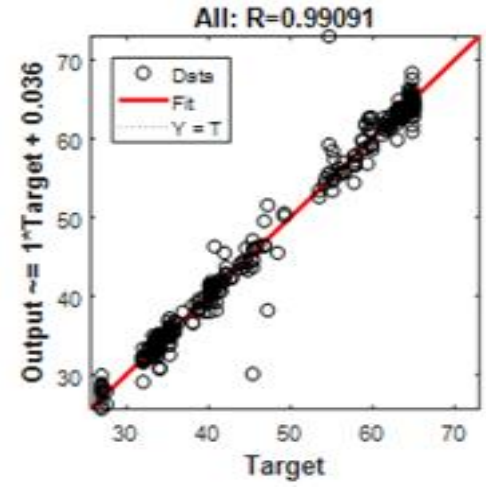

(c) All

Figure 18: Performance in model-4 using $\mathrm{R}$ as an evaluation criteria 


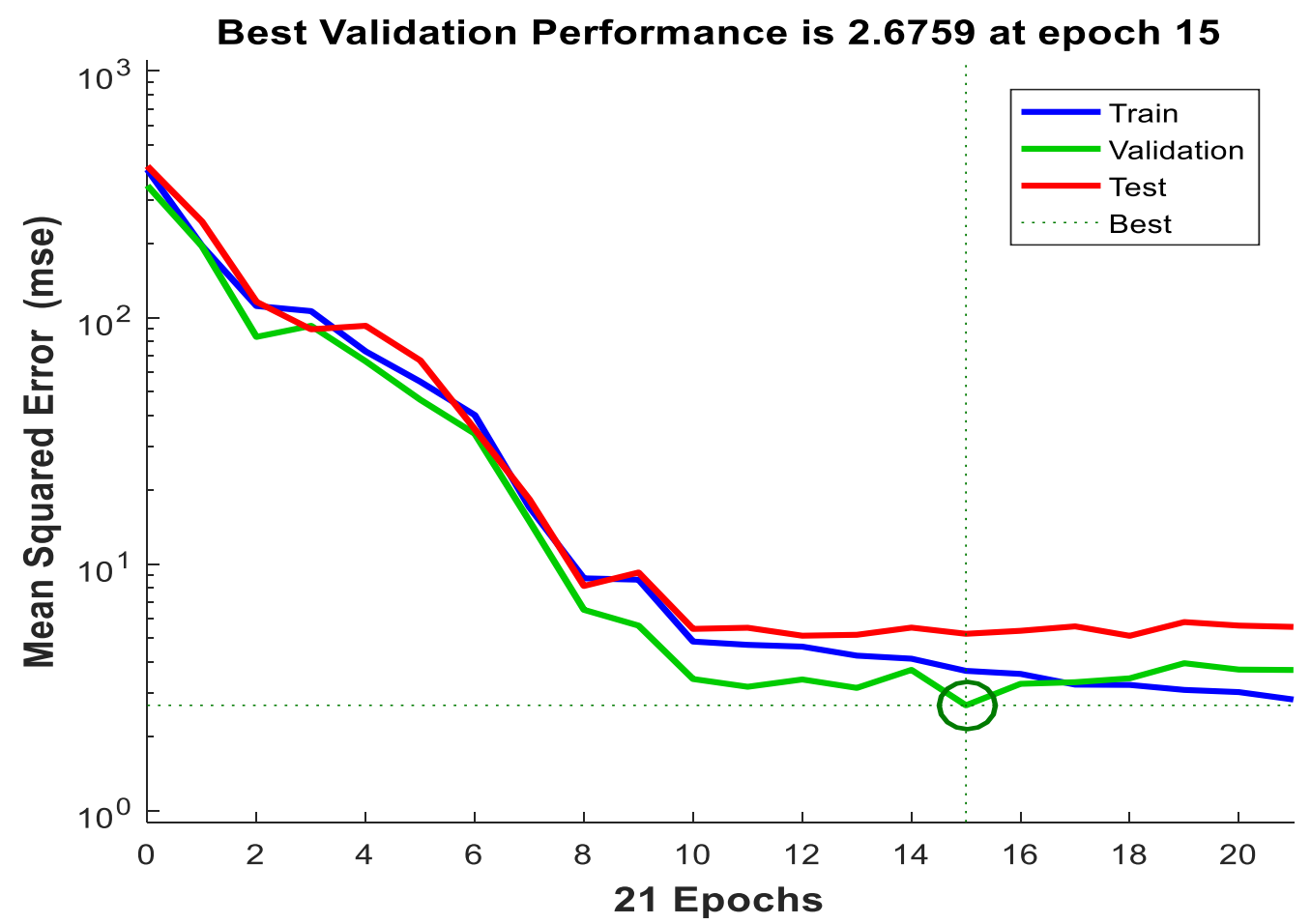

Figure 19: Performance in model-4 using MSE as an evaluation criteria

From Figure 18, the values of $\mathrm{R}$ in the training, testing and combined phases are 0.992, 0.980 and 0.991 respectively. The higher the value of $\mathrm{R}$ the better the result. This showed that the result was better in the training phase, follow by combined phase and least in the testing phase. These values were further confirmed with the values of MSE (Figure 19) $2.67 \mathrm{~m}^{3} / \mathrm{s}, 4.58 \mathrm{~m}^{3} / \mathrm{s}$ and $2.68 \mathrm{~m}^{3} / \mathrm{s}$ in the training, testing and combined phase respectively. The lower the value of MSE the better the result. Three other performance criteria (coefficient of determination, $\mathrm{R}^{2}$; modelling efficiency, $\mathrm{E}$ and index of agreement, IOA) were further used to confirm the validity of these results. In the training phase, the results are $\left(\mathrm{R}^{2}=0.984, \mathrm{E}=0.981\right.$ and IOA $\left.=0.751\right)$, testing phase $\left(\mathrm{R}^{2}=0.960, \mathrm{E}=0.978\right.$ and IOA $=0.741)$ and combined phase $\left(\mathrm{R}^{2}=0.982, \mathrm{E}=0.980\right.$ and IOA $\left.=0.750\right)$. These confirmed the previous results as the higher the value of $\mathrm{R}^{2}, \mathrm{E}$ and IOA, the better the result. But the results from Model 4 improve better than that of Model 1, Model 2 and Model 3 when the five performance criteria were compared as indicated by high values of $\left(R, R^{2}, E\right.$ and IOA) and lower values of (MSE). This indicated that the more the dataset, the better the results.

\section{Model-5:}

The results from Model 5 are shown in Figure 20 and 21.

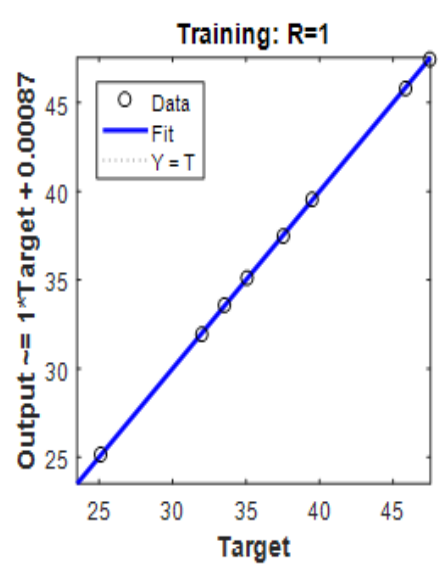

(a) Training

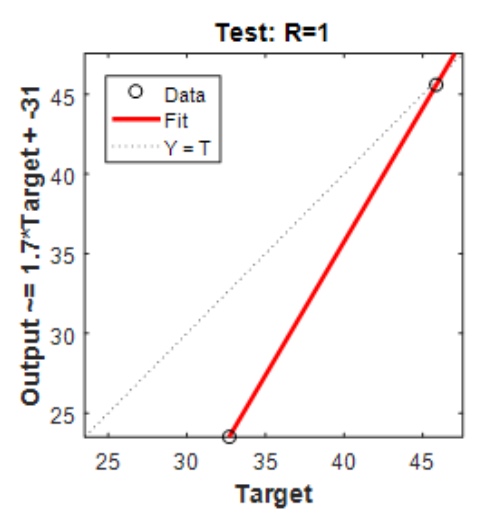

(b) Testing

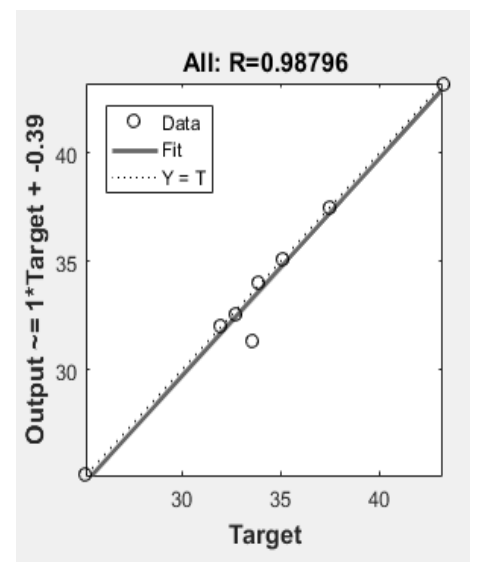

(c) All

Figure 20: Performance in model-5 using $\mathrm{R}$ as an evaluation criteria 


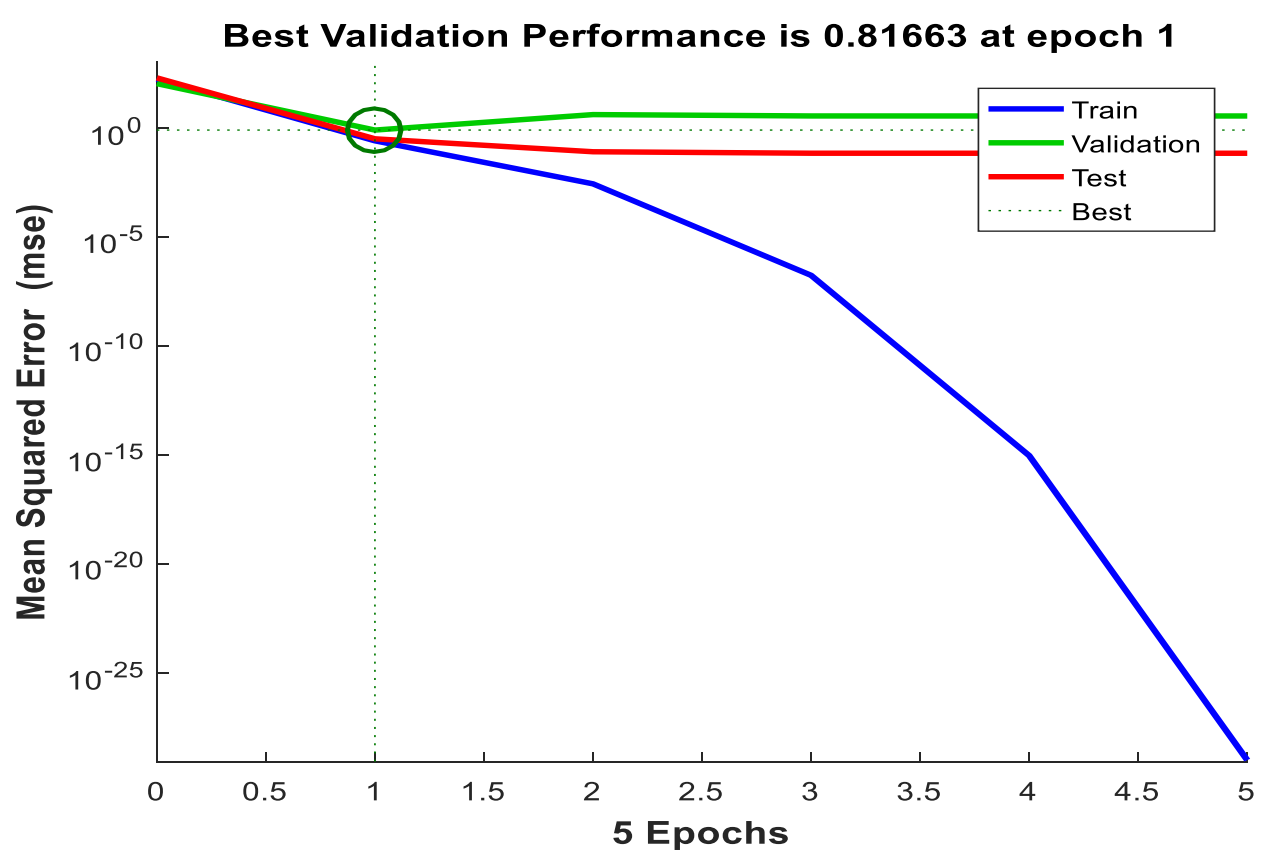

Figure 21: Performance in model-5 using MSE as an evaluation criteria

From Figure 20, the values of $\mathrm{R}$ in the training, testing and combined phases are 1.0, 1.0 and 0.988 respectively. The higher the value of $\mathrm{R}$ the better the result. This showed that the result was better in the training and testing phases and least in the combined phase. These values were further confirmed with the values of MSE (Figure 21) $0.57 \mathrm{~m}^{3} / \mathrm{s}, 0.57 \mathrm{~m}^{3} / \mathrm{s}$ and $0.987 \mathrm{~m}^{3} / \mathrm{s}$ in the training, testing and combined phase respectively. The lower the value of MSE the better the result. Three other performance criteria (coefficient of determination, $\mathrm{R}^{2}$; modelling efficiency, $\mathrm{E}$ and index of agreement, IOA) were further used to confirm the validity of these results. In the training phase, the results are $\left(\mathrm{R}^{2}=1.0, \mathrm{E}=0.991\right.$ and $\left.\mathrm{IOA}=0.872\right)$, testing phase $\left(\mathrm{R}^{2}=1.0, \mathrm{E}=0.992\right.$ and IOA $=$ $0.873)$ and combined phase $\left(\mathrm{R}^{2}=0.975, \mathrm{E}=0.987\right.$ and $\left.\mathrm{IOA}=0.842\right)$. These confirmed the previous results as the higher the value of $\mathrm{R}^{2}, \mathrm{E}$ and IOA, the better the result. But the results from Model 5 improved better than that of Model 1, Model 2, Model 3, and Model 4 when the five performance criteria were compared as indicated by high values of ( $R, R^{2}, E$ and IOA) and lower values of (MSE). This indicated that the more the dataset, the better the results. The effect of climate change incorporated into the data set in Model 5 helped improved the results very considerably as indicated by the value of $R$ and $R^{2}=1$ both in the training and testing phases (Table 3 ).

Table 3: Comparison among the five models using performance evaluation criteria using ANFIS

\begin{tabular}{|c|c|c|c|c|c|c|c|c|c|c|c|c|c|c|c|}
\hline & \multicolumn{5}{|c|}{ TRAINING } & \multicolumn{5}{|c|}{ TESTING } & \multicolumn{5}{|l|}{ ALL } \\
\hline $\begin{array}{l}\text { MODEL } \\
1\end{array}$ & 0.964 & 0.929 & 6.50 & 0.932 & 0.731 & 0.918 & 0.843 & 10.55 & 0.911 & 0.710 & 0.954 & 0.910 & 8.950 & 0.921 & 0.730 \\
\hline $\begin{array}{l}\text { MODEL } \\
2\end{array}$ & 0.969 & 0.939 & 3.77 & 0.952 & 0.735 & 0.934 & 0.872 & 6.68 & 0.942 & 0.726 & 0.960 & 0.922 & 5.570 & 0.948 & 0.732 \\
\hline $\begin{array}{l}\text { MODEL } \\
3\end{array}$ & 0.984 & 0.968 & 3.15 & 0.962 & 0.744 & 0.978 & 0.956 & 5.85 & 0.953 & 0.738 & 0.980 & 0.960 & 3.590 & 0.961 & 0.743 \\
\hline $\begin{array}{l}\text { MODEL } \\
5\end{array}$ & 1.00 & 1.00 & 0.57 & 0.991 & 0.872 & 1.00 & 1.00 & 0.57 & 0.992 & 0.873 & 0.988 & 0.976 & 0.82 & 0.987 & 0.842 \\
\hline
\end{tabular}

Table 3 showed the performance criteria data used to make comparison. Also, Figures 22-24 shows the graphs of training, testing and combined phases respectively for the five models using performance evaluation criteria. Looking at the table and the figures, it can be deduced that all the five ANFIS models performed well using training data sets, testing data sets and all the effect of the whole data sets. However, Model-5 performed better than the other models when the effect of climate change was incorporated. 


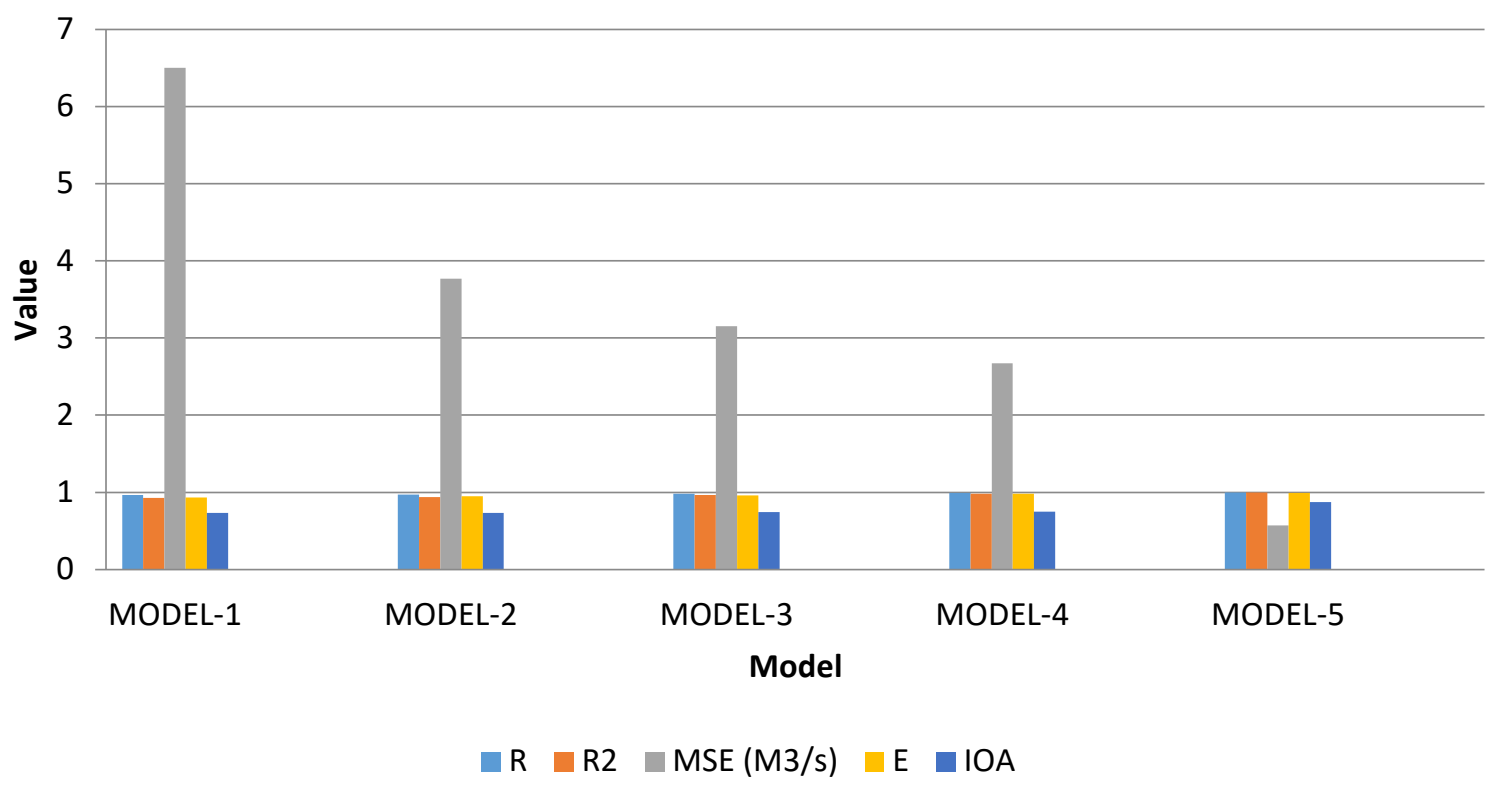

Figure 22: Performance evaluation in Model-1 to Model-5 using ANFIS (training phase)

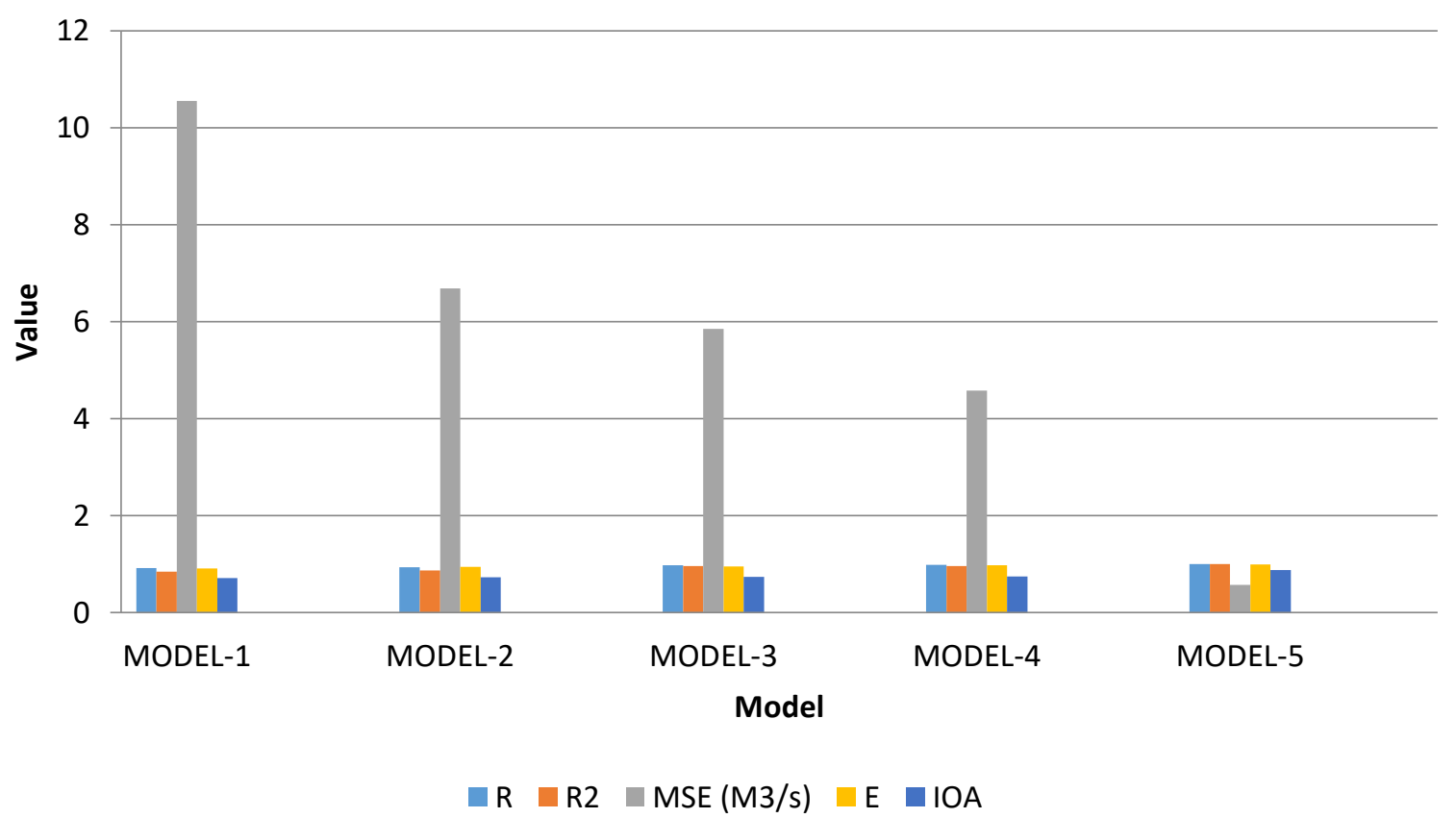

Figure 23: Performance evaluation in Model-1 to Model-5 using ANFIS (testing phase) 


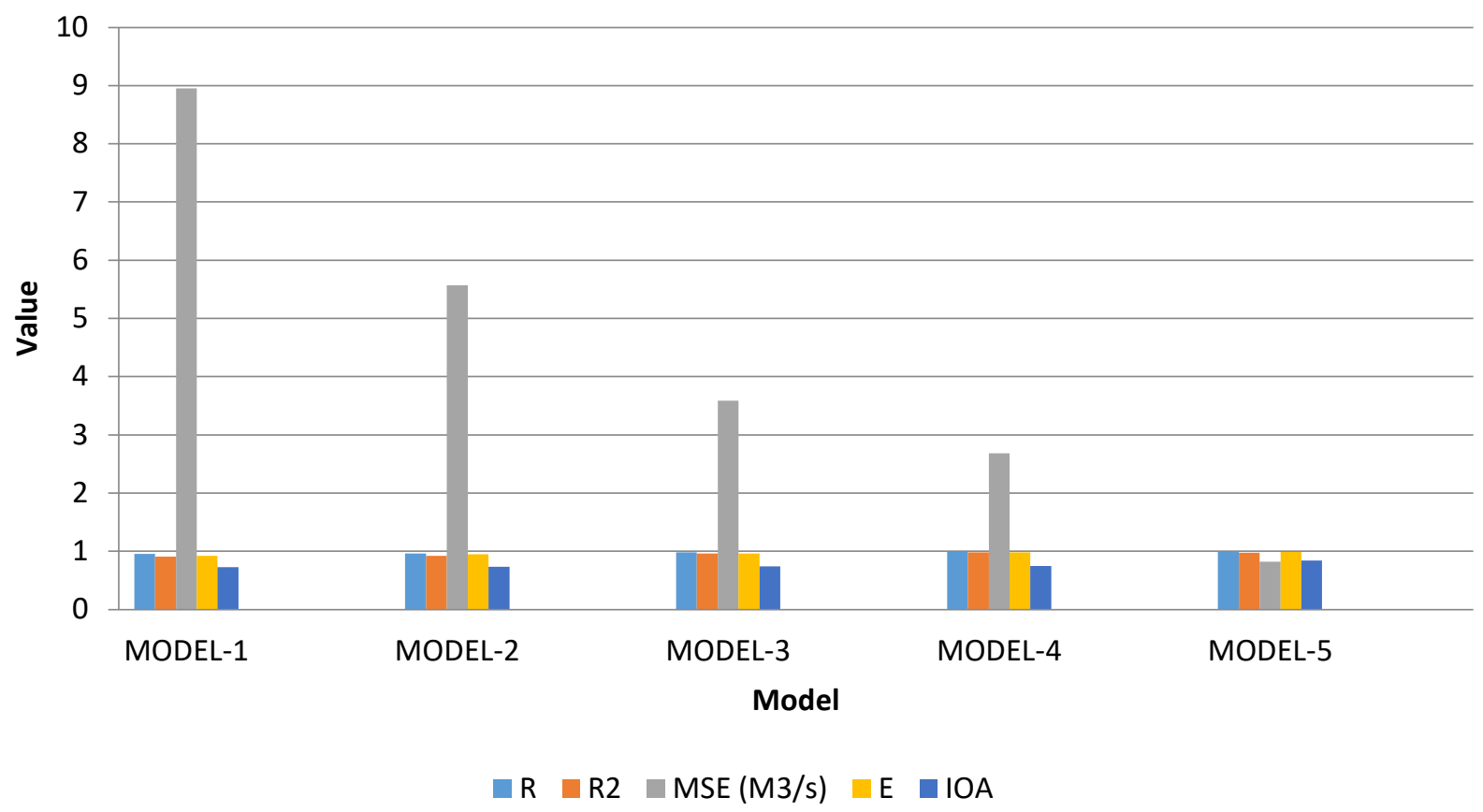

Figure 24: Performance evaluation in Model-1 to Model-5 using ANFIS (combined phase)

The training phase in Model-5 showed an over-estimation of $0.043 \%$ of the observed target output sets while an over-estimation of $0.044 \%$ was observed in the testing phase. These are within acceptable error tolerance of $+/-10 \%$ for data validation. This information is useful for integrated water resources planning and management.

\subsection{Conclusions}

This paper discuss the use of Adaptive Neuro-Fuzzy Inference System (ANFIS) which is the coupling of Artificial Neural Network (ANN) and Fuzzy Logic Inference (FLI) system in order to eliminate the disadvantages of using each singly in modelling and forecasting of River discharge.

Based on the results obtained from the studies, the following conclusions were reached:

a) Adaptive neuro-fuzzy inference system (ANFIS) is an adequate forecasting method for predicting river discharge.

b) For optimal forecasting models, effect of climate change should always be incorporated into the river discharge by indexing it with temperature and precipitation.

c) The fact that ANFIS could not train the network models perfectly with MSE of zero could be attributed to the small size of the data sets. In this case, the training data sets will not include all the representative features of the data sets the ANFIS wanted to model.

d) In situation where there are gaps in data or non-continuity in river gaping, ANFIS can be used for modelling and forecasting of river discharge for flood monitoring and forecasting and engineering design of hydraulic structures.

\section{References}

Akintola, J. O. (1986). Rainfall Distribution in Nigeria. 1892-1983. Impact Publisher, Ibadan.

Anctil, F. and Rat, A. (2005): Evaluation of neural network stream flow forecasting on 47 watersheds. J. Hydrol. Eng., 10, pp. 85-88.

Azamathulla, H. M. D. and Ghani, A. (2011) ANFIS-based approach for predicting the scour depth at culvert outlets. ASCE J Pipeline Syst Eng Pract., 2(1), pp. 35-40.

BORBDA (2005). Benin Owena River Basin Development Authority Hydrological year Book, 1989 to 2008 . 
Chang, F. J. and Chang, Y. T. (2006). Adaptive neuro-fuzzy inference system for prediction of water level in reservoir. Adv. Water Res., 29, pp. 1-10.

Chang, F. J. and Chen, Y. C. (2001). A counter propagation fuzzy-neural network modeling approach to real time stream flow prediction. J. Hydrol., 245(1-4), pp. 153-164.

Cigizoglu, H. K. and Alp, M. (2006). Generalized regression neural network in modeling river sediment yield. Adv. Eng. Softw., 37, pp. 63-68.

Cogger, K. O. (2010). Nonlinear regression methods: A survey and extensions, Intell. Syst. Acc. Fin. Manage. 17, 19-39, doi:10.1002/isaf.311.

Dastorani, M. T., Moghadamnia, A. R., Piri, J. and Rico-Ramirez, M. (2010). Application of ANN and ANFIS models for reconstructing missing flow data. Environ Monit Assess., 166, pp. 421-434.

Emiroglu, M., Bilhan, O. and Kisi, O. (2011). Neural networks for estimation of discharge capacity of triangular labyrinth side-weir located on a straight channel. Expert Syst. Appl., 38(1), pp. 867-874. doi:10.1016/j.eswa.2010.07.058.

Erinawati, R. and Fenton, J. (2012). Short-term Water Level Prediction Using Fuzzy Adaptive System and Artificial Neural Networks Approaches. 1799-1805.

Firat, M. (2007). Watershed modeling by adaptive Neuro- fuzzy inference system approach. Doctor of Philosophy Thesis, Pamukkale University, Turkey, (in Turkish).

Firat, M. and Gungor, M. (2007). River flow estimation using adaptive neuro fuzzy inference system. Math. Comput. Simulat., 75(3-4), pp. 87-96.

Jang, J. S. R. and Sun, C. T. (1995). Neuro-fuzzy and soft computing: a computational approach to learning and machine intelligence, Prentice-Hall, USA.

Maier, H. R. and Dandy, G. C. (1996). The use of artificial neural networks for the prediction of water quality parameters. Water Resources Research, 32, pp. 1013-1022.

Maity, R., Bhagwat, P. P. and Bhatnagar, A. (2010). Potential of support vector regression for prediction of monthly streamflow using endogenous property. Hydrol. Processes, 24(7), pp. $\quad 917-$ 923.

Mehta, R. and Jain, S. (2009). Optimal operation of a multi-purpose reservoir using neuro-fuzzy technique. Water Res. Manage., 23(3), pp. 509-529.

Mukarji, A., Chandranath, C. and Narendra, S. R. (2009). Flood Forecasting Using ANN, NeuroFuzzy, and Neuro-GA Models. J of Hydrologic Engineering, 14(6), pp. 647-652.

Nayak, P. C., Sudheer, K. P. and Ramasastri, K. S. (2004a). Fuzzy computing based rainfall-runoff model for real time flood forecasting. Hydrol. Process., 17, 3749-3762.

Nayak, P. C., Sudheer, K. P., Rangan, D. M. and Ramasastri, K. S. (2004b). A neuro-fuzzy computing technique for modeling hydrological time series. J. Hydrol. 291, pp. 52-66.

Nayak, P. C., Sudheer, K. P., Rangan, D. M. and Ramasastri, K. S. (2005) Short-term flood forecasting with a neurofuzzy model. Water Resour. Res. 41, pp. 2517-2530.

Owen, J. S., Eccles, B. J., Choo, B. S. and Woodings, M. A. (2001). The application of autoregressive time series modeling for the time frequency analysis of civil engineering structures. Eng. Struct., 23, pp. 521-536. 
Swain, P. and Umamahesh, N. (2004). Stream flow forecasting using neuro-fuzzy inference system. Indian J. Power River Valley Dev., 53(5/6), pp. 81-85.

Tayfur, G. and Singh, V. P. (2006). ANN and fuzzy logic models for simulating event-based rainfallrunoff; J. Hydrol. Engg., 132, pp. 1321-1330.

Valença, M. J. S and Ludermir T. B. Multiplicative-Additive Neural Networks with Active Neurons. International Joint Conference on Neural Networks (IJCNN), IEEE, Book of Summaries (2073), Washington, DC, July 1999

Wang, W. C., Chau, K. W., Cheng, C. T. and Qiu, L. (2009). A comparison of performance of several artificial intelligence methods for forecasting monthly discharge time series. J. Hydrol. 374(3-4), pp. 294-306.

Wong, J. S., Zhang, Q. and Chen, Y. D. (2010). Statistical modelling of daily urban water consumption in Hong Kong: Trend, changing patterns, and forecast. Water Resour. Res., 46, W03506, doi:10.1029/2009WR 008147

Yurdusev, M. and Firat, M. (2009). Adaptive neuro fuzzy inference system approach for municipal water consumption modeling: An application to Izmir, Turkey. J. Hydrol., 365(3-4), pp. 225- 234.

Zounemat-Kermani, M. and Teshnehlab, M. (2008). Using adaptive neuro-fuzzy inference system for hydrological time series prediction. Appl. Soft Comput. J., 8(2), pp. 928-936. 